\title{
To Sell or Not to Sell: Measuring the Heat of the Housing Market*
}

\author{
Paul E. Carrillo ${ }^{+}$ \\ Department of Economics and Elliot School of International Affairs \\ The George Washington University
}

October 2011

\begin{abstract}
Combining list-price, sale-price and time-on-the-market data, we estimate an index that summarizes housing market conditions and that has a direct economic interpretation. The index measures seller's bargaining power in a structural search model of home seller behavior. Structural estimation uncovers an analytical relationship between reduced form coefficients of hedonic and marketing-time equations and structural parameters. Thus, the index can be estimated using individual-level or aggregate data. Using housing transactions data from the Washington D.C. area, we show that index trends coincide with the up and downturns in home appreciation rates and with popular perceptions about the "heat" of the market.
\end{abstract}

Keywords: Housing Heat Index, Real Estate Market, Search Models, Asking Price, Time on the Market, Seller's Market Power, Bargaining Power

\footnotetext{
* An earlier version of this paper was circulated under the title: "To Sell or Not to Sell: List Price, Transaction Price and Marketing Time in the Housing Market.” I would like to thank the Editor and two anonymous referees, Molly Boesel, Bryan Boulier, Andra Ghent, Tara Sinclair, William Strange, Anthony Yezer, and participants at the Applied Microeconomics Seminar in George Washington University, and at the AREUEA 2011 Midyear Conference for helpful comments and discussions. I am also grateful to MRIS for sharing the data with me. All remaining errors are my own.

+ Address: 2115 G Street NW, Monroe Hall Suite 364, Washington, DC, 20052. Phone: (202) 994-7608. Email: pcarrill@gwu.edu.
} 


\section{Introduction}

Housing is one of the most important markets in the U.S. According to the Federal Reserve, the asset value of owner-occupied housing units for the entire country was approximately 16 trillion dollars in 2010. ${ }^{1}$ Housing may also be the single most important financial decision that the typical household makes. Banks and other financial institutions also invest heavily in residential real estate markets. Given the importance of this market, it is not surprising that significant efforts are made on a regular basis to measure the level and volatility of housing values, building permits, housing starts and housing inventories. Most of these statistics rely on home sales records and other administrative data from municipalities and government agencies.

In the U.S. and other developed countries, rich data documenting additional details about housing sales are generally available. Besides sale prices, these data typically contain specific details about each individual transaction such as the list price, marketing time (time on the market) and even details about the bargaining process between buyers and sellers (such as number of rejected offers). ${ }^{2}$ This type of data is generally collected by real estate agents in a database system known in the U.S. as Multiple Listing Services (MLS). Although microlevel MLS data are not always available to researchers, some real estate agents' associations compute and publish aggregate statistics such as mean list prices, mean marketing time, the share of transaction below the list price, among many others. It is clear that such statistics provide valuable information to assess housing market conditions. It is surprising,

\footnotetext{
${ }^{1}$ This information was taken from Table B.100 entitled "Balance Sheet of Households and Nonprofit Organizations" in the Federal Reserve's Flow of Funds Report which can be found at http://www.federalreserve.gov/releases/z1/current/ and was last accessed on 10/24/2011.

${ }^{2}$ Merlo and Ortalo-Magne (2004) use this kind of data to describe stylized facts about the marketing process of housing in England.
} 
however, that such indicators or indices that combine them are not currently being produced systematically in all urban areas to measure the performance of real estate. In this paper we take a first step in this direction and show how to use MLS data to construct an index that summarizes housing market conditions and that has a direct economic interpretation. ${ }^{3}$ This index measures home seller's bargaining power providing an estimate of the "heat" of the housing market.

The "heat" of the housing market has been the focus of recent works in the academic literature (Novy-Marx, 2010) and is a topic of concern for real estate practitioners. ${ }^{4}$ Despite the growing attention, we are not aware of any effort in the academic literature to empirically measure it. To measure the "heat" of the housing market we specify and estimate a structural model of home seller behavior. The estimate of one particular structural parameter that measures home seller's bargaining power describes if the housing market is a sellers' (hot) market or a buyers' (cold) market. The estimation method uncovers an analytical closedform relationship between reduced-form coefficients of hedonic and marketing-time equations and the structural parameters. Thus the structural parameter of interest (seller's bargaining power) can be computed using either (not-so-easy-to-access) MLS individual level data or (readily available) MLS aggregate data. This is the key methodological contribution of this paper.

Economic theory is used to model the relationship among seller's list prices, sale prices and marketing time and to provide a clear definition for the seller's bargaining power. The

\footnotetext{
${ }^{3}$ Carrillo and Pope (2012) use MLS data to measure the liquidity of residential real estate. They focus exclusively on the distribution of time on the market.

${ }^{4}$ For instance, the real estate industry computes (and sells) a proprietary "market heat index" of the real estate market (www.marketheatindex.com) that is similar in spirit to the parameter estimated in this paper. Due to its proprietary nature, however, details about this commercial index are not available.
} 
theoretical model is a stylized standard application of search theory to housing. Every period, sellers wait for buyers to visit and inspect their housing units. If a buyer visits, the final sale price is determined and trade may or may not occur. With a fixed known probability, the list price is a take-it-or-leave-it offer to the buyer; this probability measures the seller's bargaining power. If trade does not take place, sellers may wait for a potential buyer next period. The list price affects both the rate at which potential buyers arrive and the final sale price. In particular, a higher list price decreases the likelihood that a buyer arrives but increases the expected sale price. We focus on the steady state solution where the seller optimally picks the list price and reservation value that maximize her expected gains from searching and trade. This stylized model is parametrized to obtain a closed form solution that facilitates comparative static analysis and the estimation process.

To estimate the model, four moment conditions are derived. The model is estimated using transformations from ordinary least squares (OLS) coefficients of four reduced-form models to compute consistent estimates of the structural parameters. Reduced-form equations are estimated for i) list prices, ii) sale prices, iii) the probability that the sale price is below the list price, and iv) time on the market. This method allows adding a very large set of covariates in the structural model and estimating its parameters at a low computational cost. It illustrates in a clean and clear manner the link between the coefficients of reducedform models and the structural parameters of a home seller's search model. But, more importantly, given that the relationship between the linear reduced-form and the structural model has been uncovered, we show that some of the structural parameters can be computed using (readily available) aggregate data.

The model is first estimated using individual-level residential real estate transaction data 
from a large suburb of the Washington D.C. Metropolitan Area. The data contain more than 14,000 transactions of units that were listed on the MLS during 2006 and include information about the list price, sale price, marketing time, and a comprehensive set of the home's and neighborhood's characteristics. The estimate of our structural coefficient of interest suggests that in this market buyers and sellers had about the same level of bargaining power. Most other parameter estimates have the expected signs and have an intuitive interpretation. Moreover, the estimated model is able to replicate the pricing and duration data remarkably well. It is not surprising that the predicted means match the actual moments very closely. What is remarkable is that the model is able to simulate the whole distribution of time on the market with great accuracy. We highlight this point because marketing time is simulated using only the underlying assumptions of the model without imposing any other source of heterogeneity. The estimated structural model is used to predict the effects of list price on time on the market. We find that there is a substantially large effect of overpricing on marketing time; this effect is non-linear and increases exponentially as list price rises.

Then, for each year in the period 1998-2009, aggregate data from housing transactions in the same area, are used to compute the particular structural parameter of interest: home sellers' bargaining power. It is found that, between 2001 and 2005, sellers had most bargaining power in what appears to have been a very hot housing market. Before 2000 and after 2006, sellers' bargaining power is much lower depicting a significantly cooler and rather cold buyers' market. These trends coincide with the up and downturns in home appreciation rates in the area and are consistent with popular perceptions about the "heat" of the housing market. To show that seller's bargaining power depends on the specific location of the housing unit within the county and on the home's attributes, the index is computed by 
zip code, by age and by home type. We hope that this approach has substantial utility in other applications where index numbers of housing market conditions are needed.

Search models have been widely used to explain buyers' and sellers' behavior in the housing market (see for example, Yinger 1981, Yavas 1992, Horowitz 1992, Yavas and Yang 1995, Haurin 1998, Arnold 1999, Albrecht et al. 2007, Novy-Marx 2009, Haurin et al. 2010, Turnbull and Zahirovic-Herber 2011 and Carrillo, forthcoming, among others). Our paper adds to the previous literature by showing how the structural parameters of a home seller's search model can be related to the coefficients of reduced-form equations. In our application, this exercise allows the estimation of the seller's bargaining power even if only aggregate data were available. ${ }^{5}$ A number of empirical studies have recognized the fact that selling price and marketing time are simultaneously determined (Sirmans, Turnbull and Benjamin 1991, Yavas and Yang 1995, Forgey, Rutherford and Springer 1996, Huang and Palmquist 2001, Knight 2002, Turnbull and Dombrow 2006, and Turnbull, Dombrow and Sirmans 2006). Given the complicated relationship between list prices, sale prices and time on the market, there is no generally accepted empirical framework for dealing with endogenous variables. Our study presents an alternative approach that uses restrictions from theory (the structural model) for identification.

The rest of this document is organized as follows. Section 2 presents the theoretical and empirical model. The estimation method is discussed in the third section. In section 4, we present the data. Section 5 describes the results including the effects of list price on

\footnotetext{
${ }^{5}$ Harding et al. (2003) have used hedonic models to estimate the determinants of buyers' and sellers' bargaining power in the housing market. They analyze how different demographic traits influence bargaining power by adding characteristics of both buyers and sellers into a hedonic model. The focus of our paper is rather different. We produce an index that measures seller's bargaining power that can be estimated using individual level or aggregate data.
} 
marketing time and the computation of sellers' bargaining power. Finally, the last section concludes.

\section{The model}

\subsection{A stylized theoretical model}

The theory is a simplification of a model developed by Carrillo (forthcoming). The model below is a partial equilibrium search model where home sellers choose list prices and reservation strategies and is similar in spirit to the search model developed by Horowitz (1992) and recent work by Haurin et al. (2010). The model below ignores equilibrium effects and imposes specific functional form assumptions about housing demand. These additional assumptions facilitate finding analytical solutions to the seller's optimal strategies and its estimation.

Assume a market with infinitely-lived agents. The agents are households who either are actively searching for a home (buyers), or who have a vacant home for sale (sellers). A home is considered to be an indivisible good from which both buyers and sellers derive utility. The home's characteristics are fully captured by an index $s$ that measures the monetary value of a housing unit. ${ }^{6}$

A seller joins the housing market by placing a listing that informs all potential buyers: a) that her home is for sale, b) her list price $P_{s}$, and c) the home's characteristics (and thus $s)$. Define $u(P, s)$ as the level of utility that sellers obtain by selling a type $s$ home, which depends on the selling price $P$ and the home's characteristics. We assume that $u$ is a differentiable function strictly increasing in the first argument and decreasing in the second.

\footnotetext{
${ }^{6}$ Notice that in a perfect competitive market with no search and transactions costs, every home should sell for $s$ monetary units.
} 
Sellers wait for potential buyers to arrive at their home, and in the event that they engage

in trade, they exit the market forever.

Let buyers observe a listing and visit a particular seller at rate $q\left(P_{s}, s\right)$, which depends on the list price $P_{s}$, and the home's value $s$. In particular, it is assumed that this rate is decreasing in $P_{s}$ and increasing in $s .{ }^{7}$ When a buyer visits a home, she meets the seller and both bargain over the sale price. The bargaining game is as follows. With probability $\theta$, the seller is not willing to accept counter-offers, and the list price $P_{s}$ constitutes a take-itor-leave-it offer to the buyer. With probability $(1-\theta)$, the buyer has the option to make a counter take-it-or-leave-it offer $P_{b}$ to the seller. It will be assumed that once a buyer has visited a property, she has perfect information about the seller's preferences. That is, if she makes a counter take-it-or-leave-it offer, she will bid the seller's reservation value $R_{s}$ (the minimum price at which she is willing to sell her property). The assumption of (ex-post) perfect information simplifies the nature of the bargaining game and has been used in other studies such as Albrecht et al. (2007), for example. ${ }^{8}$

During the meeting, buyers have the option to buy the home (paying either $P_{s}$ or $P_{b}$ ), or to stay in the market. The buyer's optimal behavior is not modelled explicitly. Instead,

\footnotetext{
${ }^{7}$ Notice that a key assumption (and limitation) of our approach is the assumption that list prices are a price ceiling and a commitment device. Although restrictive, this assumption has been used in previous studies that use search theoretic approaches to explain the relationship among list prices, transaction prices and marketing time (Horowitz, 1992, Chen and Rosenthal, 1996, Arnold, 1999, Haurin et al., 2010, and Carrillo, forthcoming, for example). Lu and Strange (2011) show that properties in U.S. housing markets sometimes sell above the list price. In a recent theoretical paper, Albrecht et al. (2010) does not treat the asking price as a ceiling and also allows for the receipt of multiple simultaneous offers. When multiple offers arrive, the buyers submit sealed bids and the seller is obliged to accept the highest of these. In equilibrium, some sellers set a low list price provoking bids above it, while other sellers would set high list prices and ultimately accept a sales price below list. Structural estimation of the Albrecht et al. model is challenging due to the existence of multiple equilibrium, and we are not aware of any attempt to estimate it.

${ }^{8}$ This bargaining model simplifies the model's solution but it has several limitations. For instance, the bargaining model predicts that transaction prices occur either at the seller's posting price or reservation value and that buyers make at most one counteroffer to sellers. These implications are likely rejected by the data (Merlo and Ortalo-Magne 2004).
} 
we define $\gamma_{s}=\gamma\left(P_{s}, s\right)$ as the probability that a buyer is willing to buy a property given that she has visited it and did not have the opportunity to make a counter offer. $\gamma_{s}$ depends on both $P_{s}$ and $s$; in particular, we assume that $\gamma_{s}$ is continuous, differentiable, and that $\gamma_{s 1} \leq 0$ and $\gamma_{s 2} \geq 0$, where the subscripts denote partial derivatives. If the buyer has visited a home and had the opportunity to make a counter offer, let $\gamma_{b}=\gamma\left(R_{s}, s\right)$ be the rate at which buyers are willing to engage in trade. $\gamma_{b}$ is assumed to be a continuous, differentiable function with $\gamma_{b 1} \leq 0$ and $\gamma_{b 2} \geq 0$.

From a seller's point of view, trade occurs only if a buyer visits her property and is willing to trade, either at the list price $P_{s}$ or at her reservation value $R_{s}$. Using this consideration we are able to define the seller's expected gain from search and trading as

$$
\Pi_{t}^{e}=q\left[\theta \gamma_{s} u\left(P_{s t}, s\right)+(1-\theta) \gamma_{b} u\left(R_{s t}, s\right)\right]+\left[1-q\left(\theta \gamma_{s}+(1-\theta) \gamma_{b}\right)\right] \beta \Pi_{t+1}^{e},
$$

where $\Pi_{t}^{e}$ is the seller's value of having an opportunity to trade in each period $t$ (her value of search), $\beta$ is the seller's discount factor, and $u$ captures the seller's net utility of selling her home. ${ }^{9}$

Equation (1) states that, in every period, there is $q \theta \gamma_{s}$ probability that a seller sells her home for the list price and obtains $u\left(P_{s t}, s\right)$ profit when trading; with probability $q(1-\theta) \gamma_{b}$, trade occurs at the seller's reservation value, in which case her gain from trade is $u\left(R_{s t}, s\right)$; finally, if trade does not happen, she returns to the market and keeps her value of search $\beta \prod_{t+1}^{e}$ (the discounted value of having an opportunity to trade next period).

\footnotetext{
${ }^{9}$ One could argue that sellers in the housing market are not searching in the conventional way one thinks about search. Rather than actively searching and drawing buyers at random, they wait patiently for offers. Home sellers' behavior, however, can be and has been described by search models (see for example, Horoworitz 1992). They passively wait for random offers to arrive, incur high transaction costs and their behavior can be characterized by optimal reservation strategies. For these reasons we refer to $\Pi^{e}$ as the seller's expected gain from search and trading.
} 
Because time horizon is infinite, the seller's profit, list price and reservation price are time independent. In particular, we conjecture that there exists a steady state where $\Pi_{t}^{e}=$ $\Pi_{t+1}^{e}=\Pi^{e}$. Then, the seller's problem consists of choosing an optimal reservation value $R_{s}^{*}$ and list price $P_{s}^{*}$ that maximize her value of search. ${ }^{10}$

First, notice that any optimal seller's behavior necessarily implies that

$$
u\left(R_{s}^{*}, s\right)=\beta \Pi^{e} .
$$

That is, the minimum price that the seller is willing to accept should be such that she is indifferent between selling and the option of continued search. We replace this condition in equation (1) and obtain that, for any $R_{s}^{*}$,

$$
\Pi^{e}=\theta q \gamma_{s} u\left(P_{s}, s\right)+\left(1-\theta q \gamma_{s}\right) u\left(R_{s}^{*}, s\right) .
$$

Differentiating this equation with respect to $P_{s}$, we find that the optimal seller's list price $P_{s}^{*}$ solves:

$$
\frac{u\left(P_{s}^{*}, s\right)-u\left(R_{s}^{*}, s\right)}{u_{1}\left(P_{s}^{*}, s\right)}=\frac{1-\phi\left(P_{s}^{*}, s\right)}{\phi_{1}\left(P_{s}^{*}, s\right)} .
$$

Here the subscripts denote partial derivatives and, for notational simplicity, we have defined $1-\phi\left(P_{s}, s\right)$ as the probability that, given that the list price is a take-it-or-leave-it offer to the buyer, a home sells for the list price; that is: $1-\phi\left(P_{s}, s\right)=q\left(P_{s}, s\right) \gamma\left(P_{s}, s\right)$.

Combining equations (2) and (3), we find a new optimality condition that $P_{s}^{*}$ and $R_{s}^{*}$ must satisfy

$$
\frac{u\left(R_{s}^{*}, s\right)}{\beta}=\theta\left[1-\phi\left(P_{s}^{*}, s\right)\right] u\left(P_{s}^{*}, s\right)+\left(1-\theta\left[1-\phi\left(P_{s}^{*}, s\right)\right]\right) u\left(R_{s}^{*}, s\right) .
$$

\footnotetext{
${ }^{10}$ This is a standard approach to solve infinite-horizon search models. For details, see Lipmann and McCall (1976).
} 
The optimal steady state seller's list price and reservation value are defined by the pair $\left\{P_{s}^{*}, R_{s}^{*}\right\}$ that solves equations (4) and (5). One could characterize the general properties of the solution. ${ }^{11}$ Instead, we choose specific functional form assumptions for $q, \gamma$, and $u$ that provide us some specific insights about the properties of the model.

In particular, we assume that

$$
\begin{gathered}
q\left(P_{s}, s\right)=\left(P_{s} / s\right)^{-\lambda^{q}} ; P_{s} \geq s, \\
\gamma_{s}=\gamma\left(P_{s}, s\right)=\left(P_{s} / s\right)^{-\lambda^{s}} ; P_{s} \geq s,
\end{gathered}
$$

and

$$
\gamma_{b}=\gamma\left(R_{s}, s\right)=\left(R_{s} / s\right)^{-\lambda^{s}} ; R_{s} \geq s
$$

where $\lambda^{q}, \lambda^{s}>0$. The interpretation of equations (6), (7), and (8) is straightforward. For instance, every period, there is a $\left(P_{s} / s\right)^{-\lambda^{q}}$ probability that a buyer visits a property with a relative markup of $100^{*}\left(P_{s} / s-1\right)$ percent. Similarly, given that a buyer has visited a unit, the probability that trade occurs is $\left(P_{s} / s\right)^{-\lambda^{s}}$ if the list price is the take-it-or-leave-it offer and $\left(R_{s} / s\right)^{-\lambda^{s}}$ otherwise. Notice that both the visiting rate as well as the probability of trade (conditional on a visit) decrease with list prices. Moreover, the parameters $\lambda^{q}, \lambda^{s}$ measure how responsive buyers are to changes in list prices.

We let sellers have a type of constant-relative-risk-aversion utility function. In particular, we assume that

$$
u(P, s)=\frac{1}{1-\alpha}(P / s)^{1-\alpha}
$$

\footnotetext{
${ }^{11}$ In fact, if sellers are risk neutral $(u(x)=x)$, it can be shown that as long as, a) the hazard function $h\left(P_{s}^{*}, s\right)=\frac{\phi^{\prime}\left(P_{s}^{*}, s\right)}{1-\phi\left(P_{s}^{*}, s\right)}$ is non-decreasing in $P_{s}^{*}$, and b) $\frac{\partial \phi\left(P_{s}^{*}, s\right)}{\partial s}<0$, the optimal steady state seller's posting price and reservation value are well defined and unique. In addition, $P_{s}^{*}(\beta, s) \geq R_{s}^{*}(\beta, s) \geq s, \forall \beta, \forall s$ and these functions are increasing in both arguments.
} 
where $P$ is the sale price (either $P_{s}$ or $R_{s}$ ), and the scalar $\alpha$ is a parameter that measures the seller's taste for risk.

Given these assumptions, we are able to provide a closed form solution for the optimal seller's strategies. After some algebra (details are shown in Appendix 1), we find that

$$
P_{s}^{*}=s \cdot\left\{\frac{\theta}{r} \frac{1-\alpha}{\left(\lambda^{q}+\lambda^{s}-(1-\alpha)\right)}\right\}^{\frac{1}{\lambda^{q}+\lambda^{s}}}
$$

and

$$
\begin{aligned}
R_{s}^{*} & =P_{s}^{*} /\left\{\frac{\lambda^{q}+\lambda^{s}}{\lambda^{q}+\lambda^{s}-(1-\alpha)}\right\}^{\frac{1}{1-\alpha}} \\
& =s \cdot\left\{\frac{\theta}{r} \frac{1-\alpha}{\left(\lambda^{q}+\lambda^{s}-(1-\alpha)\right)}\right\}^{\frac{1}{\lambda^{q}+\lambda^{s}}}\left\{\frac{\lambda^{q}+\lambda^{s}}{\lambda^{q}+\lambda^{s}-(1-\alpha)}\right\}^{\frac{-1}{1-\alpha}}
\end{aligned}
$$

where $r$ is the per-period discount rate.

Proposition 1: Let $L=\frac{r}{\theta+r}\left(\lambda^{q}+\lambda^{s}\right)$ and $H=\frac{(1-\alpha) \ln \left\{\frac{\theta}{r} \frac{1-\alpha}{\left(\lambda^{q}+\lambda^{s}-(1-\alpha)\right)}\right\}}{\ln \left\{\frac{\lambda^{q}+\lambda^{s}}{\lambda^{q}+\lambda^{s}-(1-\alpha)}\right\}}$. As long as $L<1-\alpha<\lambda^{q}+\lambda^{s}<H$, then a) $P_{s}^{*} \geq R_{s}^{*} \geq s$, b) $\frac{\partial P_{s}^{*}}{\partial \theta} \geq 0$, c) $\frac{\partial P_{s}^{*}}{\partial r} \leq 0$, d) $\frac{\partial P_{s}^{*}}{\partial\left(\lambda^{q}+\lambda^{s}\right)} \leq 0$, e) $\frac{\partial\left(P_{s}^{*} / R_{s}^{*}\right)}{\partial\left(\lambda^{q}+\lambda^{s}\right)} \leq 0$, and f) $\frac{\partial P_{s}^{*}}{\partial \alpha} \leq 0$

The bounds on the parameters guarantee that the solution is well defined and that proposition 1a) holds. ${ }^{12}$ The other statements in proposition 1 are derived from differentiating equations (10) and (11) with respect to each argument and are quite intuitive. For instance, the list price and the markup increase with $\theta .{ }^{13}$ In addition, more motivated sellers (with higher discount rates) choose lower markups. Finally, if demand for homes becomes more elastic (as $\lambda^{q}+\lambda^{s}$ rises) list prices decrease.

\footnotetext{
${ }^{12}$ In order to guarantee that $P_{s}^{*} \geq R_{s}^{*} \geq s$, certain conditions must hold. First, the term that multiplies $s$ in equation (10) must be no less than one. This condition holds as long as $\frac{r}{\theta+r}\left(\lambda^{q}+\lambda^{s}\right)<1-\alpha$. Second, it must be the case that both the numerator in equation (11) and the total factor multiplying $s$ in equation (11) are no less than one. The first requirement is met as long as $0<(1-\alpha)<\lambda^{q}+\lambda^{s}$; the second is met

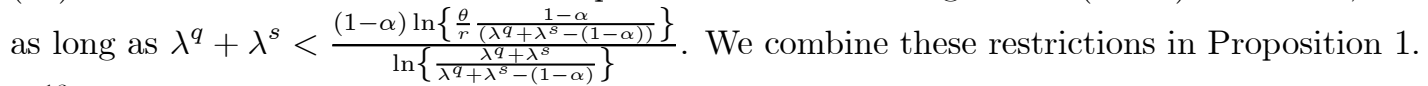

${ }^{13}$ The finding that the posting price and markup increase with $\theta$ has been found in the literature and is not driven by the functional form of the utility function. For instance, Carrillo (forthcoming) shows that this result holds even when sellers are risk neutral.
} 


\subsection{An empirical model}

Here we add seller's heterogeneity to the baseline model described in the previous section. There are $N$ sellers in the market, and each seller $i$ owns a home that is uniquely described by a vector of home characteristics $X_{i}$ and a scalar $u_{i}$. The vector $X_{i}$ includes features of the property that can be observed by both, the agents and the econometrician. These include the square footage, acreage and number of bathrooms, for example. The seller's value of other characteristics of the home that are not observed by the econometrician are captured by the variable $u_{i}$. It is assumed that $E\left[u_{i} \mid X_{i}\right]=0$ and $E\left[u_{i}^{2} \mid X_{i}\right]=\sigma_{u}^{2}$. We let the monetary value of a home be a linear index of both observed and unobserved characteristics; that is, $\ln \left(s_{i}\right)=\delta^{0}+X_{i} \delta+u_{i}$, where $\delta^{0}$ is a scalar (the constant term) and $\delta$ is a vector of parameters.

Given these assumptions, $X_{i}$ and a set of parameters $\delta$, we may use equation (10) to define log-list prices as

$$
\ln P_{s i}^{*}=\delta^{0}+X_{i} \delta+\frac{1}{\lambda^{q}+\lambda^{s}} \ln \left\{\frac{\theta}{r} \frac{1-\alpha}{\left(\lambda^{q}+\lambda^{s}-(1-\alpha)\right)}\right\}+u_{i} .
$$

Similarly, we may use equation (11) to compute the seller's log-reservation value as

$$
\ln R_{s i}^{*}=\ln P_{s i}^{*}-\frac{1}{(1-\alpha)} \ln \left\{\frac{\lambda^{q}+\lambda^{s}}{\lambda^{q}+\lambda^{s}-(1-\alpha)}\right\} .
$$

Notice that the difference between the seller's list price and reservation value is deterministic. Hence, to explain observed differences between list prices and sale prices we will later assume that seller's reservation values are measured with error.

These optimal pricing choices allow us to compute the seller's per-period unconditional probability of trade. For this, let us first work out the per-period probability that a buyer 
visits and is willing to trade given that the list price is a take-it-or-leave-it offer

$$
\begin{aligned}
\operatorname{Pr}\{\text { trade } \mid P & \left.=P_{s i}^{*}\right\}=\left(P_{s i}^{*} / s_{i}\right)^{-\left(\lambda^{q}+\lambda^{s}\right)} \\
& =\frac{r}{\theta} \frac{\left(\lambda^{q}+\lambda^{s}-(1-\alpha)\right)}{1-\alpha} .
\end{aligned}
$$

Here, $P$ is the (random) sale price and we have used equation (13) to find the optimal relative markup $P_{s i}^{*} / s_{i}$ in terms of the structural parameters. Similarly, we may compute the per-period probability of trade if trade occurs at the seller's reservation value as

$$
\begin{aligned}
\operatorname{Pr}\{\text { trade } \mid P & \left.=R_{s i}^{*}\right\}=\left(P_{s i}^{*} / s_{i}\right)^{-\lambda^{q}} *\left(R_{s i}^{*} / s_{i}\right)^{-\lambda^{s}} \\
& =\left(P_{s i}^{*} / s_{i}\right)^{-\left(\lambda^{q}+\lambda^{s}\right)} *\left(P_{s i}^{*} / R_{s i}^{*}\right)^{\lambda^{s}} \\
& =\frac{r}{\theta} \frac{\left(\lambda^{q}+\lambda^{s}-(1-\alpha)\right)}{(1-\alpha)} \cdot\left(\frac{\lambda^{q}+\lambda^{s}}{\lambda^{q}+\lambda^{s}-(1-\alpha)}\right)^{\frac{\lambda^{s}}{1-\alpha}}
\end{aligned}
$$

Thus, the seller's unconditional probability of trade in any given period is defined by

$$
\begin{aligned}
\omega & =\theta \operatorname{Pr}\left\{\text { trade } \mid P=P_{s}^{*}\right\}+(1-\theta) \operatorname{Pr}\left\{\text { trade } \mid P=R_{s}^{*}\right\} \\
& =\frac{r\left(\lambda^{q}+\lambda^{s}-(1-\alpha)\right)}{\theta(1-\alpha)}\left[\theta+(1-\theta)\left(\frac{\lambda^{q}+\lambda^{s}}{\lambda^{q}+\lambda^{s}-(1-\alpha)}\right)^{\frac{\lambda^{s}}{(1-\alpha)}}\right] .
\end{aligned}
$$

This finding along with the other assumptions about the trading mechanism implies that the time that property $i$ stays on the market, $T_{i}$, follows a geometric distribution. That is,

$$
\operatorname{Pr}\left\{T_{i}=t\right\}=\omega(1-\omega)^{t-1}
$$

\section{Estimation}

In this section, we derive a set of moment conditions that facilitate the estimation of the structural model. We assume at first that individual-level transaction data are available and

develop an estimation method using this type of data. Then, we show how some structural parameters can be estimated using aggregate data. 


\subsection{Moment conditions}

Assume that individual transaction data are available, and let $p_{s i}, p_{m i}, t_{i}$ and $X_{i}$ be the actual list price, sale price, time on the market and observed characteristics of property $i, i=1 . . n$. We assume that list prices $\left(p_{s i}\right)$ and market prices that occur at the list price $\left(p_{m i} \mid p_{s i}=p_{m i}\right)$ are accurately measured. On the other hand, we assume that market prices that are below the list price are measured with error (classical i.i.d. measurement error); that is, $\left[\ln p_{m i} \mid p_{s i} \neq p_{m i}\right]=\ln R_{s i}^{*}+\varepsilon_{i}$, where $E\left[\varepsilon_{i}\right]=0 .{ }^{14}$

With these assumptions, we use equation (13) to derive the first moment equation

$$
E\left[\ln P_{s i}^{*} \mid X_{i}\right]=\delta^{0}+X_{i} \delta+\frac{1}{\lambda^{q}+\lambda^{s}} \ln \left\{\frac{\theta}{r} \frac{1-\alpha}{\left(\lambda^{q}+\lambda^{s}-(1-\alpha)\right)}\right\}
$$

The second moment condition is derived by computing the expected value of the sale price.

Let $P_{i}$ be the (random) sale price of a unit. Then,

$$
\begin{aligned}
E\left[\ln P_{i} \mid X_{i}\right] & =\tilde{\theta} E\left[\ln P_{s i}^{*} \mid X_{i}\right]+(1-\tilde{\theta}) E\left[\ln R_{s i}^{*} \mid X_{i}\right] \\
& =E\left[\ln P_{s i}^{*} \mid X_{i}\right]-(1-\tilde{\theta}) E\left[\ln P_{s i}^{*}-\ln R_{s i}^{*} \mid X_{i}\right] \\
& =E\left[\ln P_{s i}^{*} \mid X_{i}\right]-(1-\tilde{\theta}) \frac{1}{1-\alpha} \ln \left\{\frac{\lambda^{q}+\lambda^{s}}{\lambda^{q}+\lambda^{s}-(1-\alpha)}\right\},
\end{aligned}
$$

where we have used equation (14) to compute $E\left[\ln P_{s i}^{*}-\ln R_{s i}^{*} \mid X_{i}\right]$. Here $\tilde{\theta}$ is the probability that the list price is the sale price given that trade occurs; that is $\tilde{\theta}=\operatorname{Pr}\left\{P=P_{s i}^{*} \mid \operatorname{trade}\right\}$.

\footnotetext{
${ }^{14}$ As we discussed earlier we need to assume measurement error to be able to explain heterogeneity in differences between list and market prices.
} 
We may use Bayes' rule to compute $\tilde{\theta}$ as a function of the structural parameters

$$
\begin{aligned}
\tilde{\theta} & =\frac{\theta \operatorname{Pr}\left\{\operatorname{trade} \mid P=P_{s}^{*}\right\}}{\theta \operatorname{Pr}\left\{\operatorname{trade} \mid P=P_{s}^{*}\right\}+(1-\theta) \operatorname{Pr}\left\{\operatorname{trade} \mid P=R_{s}^{*}\right\}} \\
& =\frac{\theta \frac{r}{\theta} \frac{\left(\lambda^{q}+\lambda^{s}-(1-\alpha)\right)}{1-\alpha}}{\theta \frac{r}{\theta} \frac{\left(\lambda^{q}+\lambda^{s}-(1-\alpha)\right)}{1-\alpha}+(1-\theta)\left(\frac{r}{\theta} \frac{\left(\lambda^{q}+\lambda^{s}-(1-\alpha)\right)}{1-\alpha} \cdot\left(\frac{\lambda^{q}+\lambda^{s}}{\lambda^{q}+\lambda^{s}-(1-\alpha)}\right)^{\frac{\lambda^{s}}{1-\alpha}}\right)} \\
& =\frac{1}{1+\frac{(1-\theta)}{\theta}\left(\frac{\lambda^{q}+\lambda^{s}}{\lambda^{q}+\lambda^{s}-(1-\alpha)}\right)^{\frac{\lambda^{s}}{1-\alpha}}} .
\end{aligned}
$$

Before we continue with the derivation of the moment equations, it is useful at this point to analyze $\Delta=E\left[\ln P_{s i}^{*} \mid X_{i}\right]-E\left[\ln P_{i} \mid X_{i}\right]$, the difference between expected $\log$ list prices and expected log sales prices. Clearly, $\Delta$ depends on all structural parameters. Given our special interest on the seller's bargaining power, it is important to assess how changes of this parameter affect this difference. After simple differentiation, we are able to find that $\partial \tilde{\theta} / \partial \theta>0$; that is, as the seller's bargaining power increase, so does the share of home sales that occur at the list price. This is not surprising, given the nature of the bargaining game. The model also predicts that as the housing market becomes stronger (when $\theta$ raises) the difference between the list price and the expected sale price decreases: $\partial \Delta / \partial \theta<0$. When sellers' market power increases, not only are they less likely to accept counteroffers but, also, the difference between the list price and reservation price decreases. This finding is interesting and is consistent with an empirical regularity: in strong housing markets, the difference between list and sales prices tends to be smaller.

Let us now turn back to the derivation of the third moment equation. Define $Y_{i}$ as one if the sale price is different than the list price and zero else. Then, the third moment equation is defined by

$$
E\left[Y_{i}=1-\tilde{\theta}\right]
$$


Let us derive one additional moment condition. Since time on the market follows a geometric distribution, the expected value of the time $T$ that property $i$ stays on the market is defined by

$$
E\left[T_{i}\right]=\frac{1}{\omega}
$$

Notice that time on the market depends entirely upon the structural parameters (does not depend on $X_{i}$ ).

We use the moment conditions (18), (19), (20), and (21) to estimate the model. In particular, our estimates are the ones that minimize the distance between the observed and predicted moments so that, if possible, the following conditions hold:

$$
\begin{aligned}
& E\left[\ln p_{s i}-\ln P_{s i}^{*} \mid X_{i}\right]=0 \\
& E\left[\ln p_{m i}-\ln P_{i} \mid X_{i}\right]=0 \\
& E\left[1\left(p_{s i} \neq p_{m i}\right)-Y_{i}\right]=0
\end{aligned}
$$

and

$$
E\left[t_{i}-T_{i}\right]=0
$$

where $1($.$) is the indicator function. .^{15}$

\subsection{Identification}

The structural parameters of the model are $\alpha, \lambda^{q}, \lambda^{s}, \delta^{0}, \delta, r, \theta$ and $\sigma_{u}^{2}$. First, notice that $\sigma_{u}^{2}$ and $\delta$ are identified by the covariation between the home's characteristics and prices. There remain six parameters to be identified (that can shift the predicted means) and four moment conditions. Hence, some normalization is needed.

\footnotetext{
${ }^{15}$ In the empirical section, we estimate $1\left(p_{s i} \neq p_{m i}\right)$ with the share of transactions that take place below the original list price. This in an accurate approximation as long as the variance of the measurement error $\varepsilon$ is small.
} 
Because we do not observe the number of visits (nor the time period between visits) that a seller receives before she trades her home, it seems natural to make assumptions about the value of $\lambda^{q}$. In addition, we choose to calibrate the discount rate $r$ because it is easier to select a plausible value for this coefficient than it is for the other parameters. The main results of the paper are robust to these normalization choices.

\subsection{Estimation with OLS}

To estimate the model we use a simple approach that uses transformations from the OLS coefficients of the reduced-form equations to compute consistent estimates of the structural parameters. This method is straightforward. A pooled OLS regression of the four moment equations directly identifies $\sigma_{u}^{2}$ and $\delta$. We are left with four constant terms (from the OLS regression) and four structural parameters that remain to be identified. After some algebra, we find a closed form solution for the structural parameters as a function of the constant terms of the OLS regressions. ${ }^{16}$ For instance, let $\hat{\kappa}^{p_{s}}, \hat{\kappa}^{p_{m}}, \hat{\kappa}^{d}$, and $\hat{\kappa}^{T}$ be the estimates of the constant terms of the (reduced-form) moment conditions 1, 2, 3 and 4, respectively. The structural parameters are then estimated as follows:

$$
\begin{aligned}
\hat{\alpha} & =1-\frac{\hat{\kappa}^{d}}{\hat{\kappa}^{p_{s}}-\hat{\kappa}^{p_{m}}} \ln \left\{1+\frac{\hat{\kappa}^{T} r}{1-\hat{\kappa}^{d}}\right\}, \\
\hat{\lambda}^{s} & =(1-\hat{\alpha})\left(1+\frac{1-\hat{\kappa}^{d}}{\hat{\kappa}^{T} r}\right)-\lambda^{q}, \\
\hat{\theta} & =\frac{1}{1+\frac{\hat{\kappa}^{d}}{1-\hat{\kappa}^{d}} \exp \left\{-\hat{\lambda}^{s} \frac{\hat{\kappa}^{p_{s}}-\hat{\kappa}^{p_{m}}}{\hat{\kappa}^{d}}\right\}}, \\
\hat{\delta}^{0} & =\hat{\kappa}^{p_{s}}-\frac{1}{\lambda^{q}+\hat{\lambda}^{s}} \ln \left\{\frac{\hat{\theta}}{r} \frac{1-\hat{\alpha}}{\lambda^{q}+\hat{\lambda}^{s}-(1-\hat{\alpha})}\right\} .
\end{aligned}
$$

Standard errors can be computed using the delta method.

\footnotetext{
${ }^{16}$ Details of the derivation are provided in Appendix 2.
} 
We choose to keep the model as simple as possible and estimate it with OLS for the following reasons. This approach allows the parameters of a large set of covariates in the structural model to be estimated at low computational cost. It illustrates in a clean and clear manner the link between the coefficients of hedonic and time-on-the-market reduced-form equations and the structural parameters of a home seller's search model. More importantly, the proposed method can be used to recover some of the structural parameters even if only aggregate data were available. Because structural parameters have a direct economic interpretation, they can be used as indices that summarize housing market conditions. In this paper, we focus our attention on measuring seller's bargaining power.

\subsection{Estimation using aggregate data}

Micro data on individual housing transactions are generally not readily available. Instead, aggregate data such as average list prices, average sale prices and average time on the market are often published by regional MLS associations to measure the performance of local real estate markets over time. Because the relationship between reduced-form coefficients and the structural parameters of the seller's search model has been uncovered, some structural parameters can be computed using readily available aggregate data. This is particularly useful given the necessity to assess current housing market conditions.

To estimate structural parameters using aggregate data from housing transactions one needs the following information: (i) mean log list prices, (ii) mean log sale prices, (iii) the share of transactions that occurred at a price below the list price, and (iv) mean number of days that a property stays on the market. Notice that these are unconditional means. Because there are no covariates to consider, variables (i)-(iv) are equivalent to the coefficients 
$\hat{\kappa}^{p_{s}}, \hat{\kappa}^{p_{m}}, \hat{\kappa}^{d}$, and $\hat{\kappa}^{T}$, respectively. Equations (22)-(25) can be then used to recover the structural parameters of interest.

\section{Data}

To estimate the structural model, we require real estate transactions data including information on list prices, sale prices, time on the market, and home's characteristics. Such data have been collected for all residential real estate transactions in Fairfax County, VA, that were listed on the local MLS between January and December 2006 and sold before July 2007. Fairfax County is located in Northern Virginia and is part of the Washington, DC, metropolitan area,

The data come from the regional MLS and have information about units' list and sale prices, number of days on the market, and detailed property characteristics. ${ }^{17}$ The MLS data is complemented with information from other sources. For instance, using geocode information, we match the MLS records with Fairfax County's assessor database. The assessor database contains a complete set of the unit's characteristics that were not always available in the MLS listings. ${ }^{18}$ In addition, most of the observations could be matched with U.S. Census data at the Block-Group level and include several Census variables that may explain neighborhood desirability.

Table 1 shows a list of the relevant variables. The list price, the sale price and the time that the unit was on the market provide information about the transaction. ${ }^{19}$ The

\footnotetext{
${ }^{17}$ Our sample excludes properties a) not listed on the MLS, b) listed on the MLS and withdrawn from the market, and c) listed on the MLS and still active by June 302007.

${ }^{18}$ For example, a large percentage of our MLS data lacked information on square footage. By using the assessors database, we were able to obtain this information and use this variable in our models.

${ }^{19}$ We record the original asking price at the time the listing was posted. Time on the market is defined as the number of days from the date when the unit is first listed until the contract is signed.
} 
property characteristics include the unit's square footage, number of bathrooms, number of bedrooms and age, among others. In addition, we identify if the unit is a detached residence or a townhome. Finally, we compute seven variables from the U.S. Census that capture the demographic composition of the Census Block Group where the unit is located. They include the population density, proportion of Blacks and Hispanics and median household income, among others. Our final matched database consists of 14,182 records.

[Insert Table 1]

Descriptive statistics are shown in Table 2. The average sale price was $\$ 528,400$ with a minimum of $\$ 125,000$ and a maximum of $\$ 1,995,000 .{ }^{20}$ In addition, most properties (about two thirds) sold below the list price. In this sample, most homes were sold relatively quickly. While the mean time that a home stayed on the market was 55 days, 14 percent of the properties sold in less than one week, and fifty percent sold in less than 38 days. On the other hand, a small number of homes (about 10 percent) stayed on the market for more than four months. A typical home in Fairfax County is about 26 years old, has 1,709 square feet, two bathrooms, and 0.2 acres of land. In addition, an average home in our sample is located in a U.S. Census block-group where 8 percent of its population is black and 8 percent of the population is older than $65 .{ }^{21}$ There is significant dispersion in the characteristics of the neighborhoods. For example, while there are many areas in our sample with virtually no Blacks or Hispanics living in them, there are several Census block-groups that are populated by these groups only.

[Insert Table 2]

\footnotetext{
${ }^{20}$ We exclude from our database properties that were sold for more than $\$ 2,000,000$.

${ }^{21}$ Notice, however, that the Census variables' statistics are weighted by the number of homes sold in each Census block-group and do not necessarily represent an accurate description of the whole population of Fairfax County. Instead, they describe only those locations where real estate transactions were made.
} 
The model can also be estimated using aggregate data. For this reason, we have computed aggregate indicators of the Fairfax County housing market using information from the MLS for each year in the period 1998-2009. Average (log) list prices, (log) sale prices, marketing time, and the share of transactions where the market price was below the list price have been computed. ${ }^{22}$

Figures 1 and 2 show how these variables have evolved over time. Housing market conditions during the 2001-2005 period contrast with those in other years. For example, between 2002 and 2005, average list prices are only about 1 percent higher than sale prices and the mean home price appreciation is close to 70 percent. Price discounts below the list price are not often granted, and the average home seller waits for about 3 weeks before selling her home. Presumably, these conditions are consistent with a hot housing market where sellers have most of the bargaining power (a seller's market). Before 2000 and after 2006, the housing market is significantly cooler (buyer's market): the gap between list and market prices is much larger and a large portion of sellers are willing to trade at a price lower than the list price.

[Insert Figure 1]

[Insert Figure 2]

\section{Results}

In this section, the model is first estimated using individual-level housing transaction data; this exercise allows us to test the within sample fit of the model and to analyze the relationship between list prices and marketing time. Then, aggregate data are used to compute the

\footnotetext{
${ }^{22}$ To compute the aggregate indicators, we use an average of 19,000 transactions per year.
} 
structural parameter of interest: home sellers' bargaining power.

\subsection{List prices and marketing time}

Individual-level data described in the previous section are used to estimate the model, and parameter estimates are shown in Tables $3 \mathrm{a}$ and $3 b^{23}$ Table $3 \mathrm{a}$ displays the first set of structural parameters. The estimate of $\alpha$ is positive suggesting that home sellers dislike risk. For the relevant range of values, however, this function is quite linear. ${ }^{24} \lambda^{s}$ is positive and quite large, suggesting that buyers are quite responsive to changes in list prices. The estimate of our main parameter of interest $\theta$ is close to 0.5 . This means that in about 50 percent of the buyer-seller meetings, the list price was a take-it-or-leave-it offer to the buyer, suggesting that buyers and sellers shared the same level of bargaining power. We provide a careful discussion about this parameter in the next section.

[Insert Table 3a]

[Insert Table 3b]

In the first column of Table $3 \mathrm{~b}$ we show estimates for $\delta^{0}$ and $\delta$. The second column presents coefficients of a standard hedonic model where the dependent variable is the log of the sale price and the independent variables include the same set of controls used in the structural equations. The coefficients of the hedonic model show the marginal willingness to pay for each of the home's characteristics. The structural parameter $\delta$ describes how the intrinsic value of a home changes when the features of the housing unit vary. Thus, we expect $\delta$ to be close to the coefficients of a hedonic model. As expected, every coefficient has

\footnotetext{
${ }^{23}$ For estimation, we have normalized the values of the annual discount rate and $\lambda^{q}$ to 0.04 and 1 , respectively.

${ }^{24}$ The relevant variable for the utility function is the ratio of the asking price to the value of the home. Our model suggests that the average ratio is 0.26 . The estimated function $u(x)$ is essentially linear when $x \epsilon[0,1]$.
} 
the same sign and is quite close in magnitude.

Notice from Proposition 1 that the model is well defined for a bounded set of parameters. Although the estimation method does not impose any restrictions, the estimates lie within the required bounds. We interpret this as (informal) evidence that the model is correctly specified.

Before we use the estimated model to perform comparative statics, it is useful to assess its ability to fit the data. Within our sample, we use the estimates of the structural model and simulation methods to predict list prices, sale prices, and time on the market. Mean loglist prices and mean log-sale prices can be directly computed using equations (18) and (19). We simulate time on the market using the estimated coefficients and the structure imposed by the model. That is, marketing is simulated by obtaining independent realizations of a random variable with a probability distribution defined by equation (17). Results are shown on Tables 4a and 4b.

[Insert Table 4a]

[Insert Table 4b]

Given our estimation method, it is not surprising that the predicted means match the actual moments very closely. What is remarkable is that the model is able to simulate the whole distribution of time on the market with great accuracy. This is evidenced in Table 4b and in Figure 3. We highlight this point because marketing time is simulated using only the underlined assumptions of the model without imposing any other source of heterogeneity.

[Insert Figure 3]

How do list prices affect the marketing process of a housing unit? The large estimate of $\lambda^{s}$ suggests that buyers are quite responsive to changes in list prices. To get more insights 
on this, the estimated model is used to compute the effects of changing the list price on time on the market. To perform this exercise, we pick a representative unit with a list price of $\$ 530,000$ that expects to be sold in 55 days. We vary the list price and use the structural model to calculate the expected marketing time. Results are shown in Figure 4. We find that there is a substantially large effect of overpricing on marketing time. This effect is non-linear and increases exponentially as the markup rises. For instance, if the markup, the ratio of the list price to the expected sale price, increases by 1 percentage point, the expected time on the market rises by about 10 days; if the mean ratio raises by 10 percentage points, however, marketing time is expected to increase by approximately 200 days.

The effects of list prices on marketing time found here are larger than similar effects documented by other studies (Belkin, Hempel and McLeavey 1976, Kang and Gardner 1989, Yavas and Yang 1995, Knight 2002, Anglin, Rutherford and Springer 2003, and Allen, Rutherford and Thomson 2009, for example). ${ }^{25}$ Due to unobserved heterogeneity, however, it is likely that results from previous studies understate the impact of list prices on marketing time. For instance, it is likely that the unexplained residual in a hedonic equation is negatively correlated with the unexplained portion of a time-on-the-market model. That is, a home that has desirable "unobserved" features may sell at higher price and, other things equal, faster. Since list prices and sale prices are highly correlated, the markup variable may be negatively correlated with the error term of the duration equation as well. Thus, the coefficient on the markup variable could have a negative bias understating the effects of overpricing. The

\footnotetext{
${ }^{25}$ The common empirical approach used by many of these studies is intuitive and straightforward. In a duration model, an explanatory variable that measures the seller's "markup," the (percentage) difference between the posting price and the true value of the home, is included. Since the true value of the unit is unobserved, it is usually replaced by the expected price estimated using a hedonic equation. The coefficient on the markup variable estimates the effects of misspricing on time on the market.
} 
structural model we estimate solves this problem by explicitly modeling and controlling for unobserved housing heterogeneity.

[Insert Figure 4]

\subsection{Buyers' market? Sellers' market?}

In hot housing markets home sellers have most of the bargaining power and generally have the ability to set prices. In cold housing markets the opposite is true. The structural model developed in this paper provides a natural measure of housing market heat: the seller's bargaining power $\theta$. A value of $\theta$ close to one would suggest that in most meetings the list price is a take-it-or-leave-it offer to the buyer. This case would be consistent with a "seller's market" where sellers have the ability to set prices, and discounts below the list price are rarely granted. Similarly, a low value of $\theta$ may be consistent with the opposite, a "buyer's market" where buyers set prices and take enough time to consider all their options before engaging in trade.

The estimate of $\theta$ using the individual-level data is about 0.5 suggesting that home buyers and home sellers had a similar amount of bargaining power in 2006. Does this estimate change over time? The theoretical model we develop is stationary and is consistent with an environment where parameters do not change with time. One may assume, however, that the "steady state" changes from one year to another. We think this is a reasonable assumption because most, if not all, homes in our sample stay on the market for less than one year. ${ }^{26}$

If individual transaction records were available, one could easily replicate the calculations above and estimate $\theta$ for other periods. As we mentioned in an earlier discussion, individual

\footnotetext{
${ }^{26}$ Stationarity is a key assumption and a key limitation of our model. Future research is needed to understand how market conditions evolve in a non-stationary environment.
} 
housing transaction data are not always available. Given the properties of our estimation method, $\theta$ may be computed using readily available aggregate data. For instance, equation (24) can be arranged to provide an analytical expression for $\hat{\theta}$ as a function of the sample moments:

$$
\hat{\theta}=\frac{1}{1+\frac{\hat{\kappa}^{d}}{1-\hat{\kappa}^{d}} \exp \left\{\lambda^{q} \frac{\hat{\kappa}^{p_{s}}-\hat{\kappa}^{p_{m}}}{\hat{\kappa}^{d}}\right\}\left\{\frac{1-\hat{\kappa}^{d}}{1-\hat{\kappa}^{d}+\hat{\kappa}^{T} r}\right\}^{1+\frac{1-\hat{\kappa}^{d}}{\hat{\kappa}^{T}}}} .
$$

$\theta$ is estimated using equation (26) and aggregate data from housing transactions in Fairfax County, VA. For each year in the period 1998-2009, (i) mean log list prices $\left(\hat{\kappa}^{p_{s}}\right)$, (ii) mean $\log$ sale prices $\left(\hat{\kappa}^{p_{m}}\right)$, (iii) the share of transactions that occurred below the list price $\left(\hat{\kappa}^{d}\right)$, and (iv) mean number of days that a property stays on the market $\left(\hat{\kappa}^{T}\right)$ are used to compute $\hat{\theta}$, the estimate of the Fairfax County seller's bargaining power. ${ }^{27}$ Results are displayed in Figure 5. Between 2000 and 2005, sellers had most bargaining power in what appears to have been a very hot housing market. Before 2000 and after 2006, low values of $\hat{\theta}$ are consistent with a much cooler and rather cold buyers' market. These trends coincide with the swings in home appreciation rates in the area and are consistent with popular perceptions about the "heat" of the housing market. ${ }^{28}$

\section{[Insert Figure 5]}

Researchers and real estate practitioners may also be interested to test if the seller's bargaining power $\theta$ depends on the housing unit's location or on its characteristics. Using aggregate data one can compute different estimates of $\theta$ for each type of home and/or for

\footnotetext{
${ }^{27}$ In all calculations the values of the daily discount rate $r$ and $\lambda^{q}$ have been set to 0.0001 and 1 , respectively. Notice that time on the market is measured in days. Thus, to compute the index, one needs to use a daily discount rate $r$ rather than an annual discount rate. A daily discount rate of 0.0001 is equivalent to an annual discount rate of about 0.04 .

${ }^{28}$ Standard errors can be computed using the delta method. Given our sample size, all estimates are statistically significant at any conventional significance level.
} 
each specific location. For example, the index has been computed for each zip code in Fairfax County (for the year 2006) and results are shown in Figure 6. As it was the case with the yearly indices, only aggregate data (for each zip code) are needed. Results show evidence that home seller's bargaining power depends on the unit's specific location: it seems that in the South-East region of the county the housing market was particularly "hotter" during that period.

\section{[Insert Figure 6]}

We also estimate $\theta$ for different types of housing units and show results in Figure 7. After 2000, the bargaining power of sellers of detached units (single family homes) is generally lower than that of sellers of townhomes and condominiums. In the late 1990s, however, the market of detached units seems to have been "hotter" that the market for condominiums. Finally, the index has been estimated for new (less than two year old) and older units. Results shown in Figure 8 suggest that sellers of new housing units (perhaps developers) consistently have a larger degree of bargaining power compared to sellers of older homes. During the boom (between 2002 and 2005), however, the differences in bargaining power between these two groups largely decreased.

[Insert Figure 7]

[Insert Figure 8]

It is useful at this point to assess how changes in $\hat{\kappa}^{p_{s}}-\hat{\kappa}^{p_{m}}, \hat{\kappa}^{d}$, and $\hat{\kappa}^{T}$ affect $\hat{\theta}$, and how these changes are able to account for the observed variation of the index. First, let us analyze how the difference between mean log posting and mean log market price affects the housing heat index. Equation (26) predicts that, the larger this difference the lower the seller's bargaining power. This prediction has an intuitive interpretation: in housing 
markets where sellers have most of the bargaining power, the average gap between list prices and transaction prices is generally smaller. To analyze how variation of this gap determines changes in $\hat{\theta}$, we first compute the mean and standard deviation of the average annual gap. Then we evaluate $\hat{\theta}$ when $\hat{\kappa}^{p_{s}}-\hat{\kappa}^{p_{m}}$ increases (decreases) by one standard deviation from the mean (while keeping the other variables constant). This exercise is shown in Table 5. The first two rows display the 1997-2009 means and standard errors of the index components. The estimate of theta evaluated at the sample means is about 0.69 . When one standard deviation is added to (subtracted from) $\hat{\kappa}^{p_{s}}-\hat{\kappa}^{p_{m}}$, while keeping the other variables constant at their means, $\hat{\theta}$ decreases (increases) to $0.68(0.70)$. These results suggest that changes in $\hat{\kappa}^{p_{s}}-\hat{\kappa}^{p_{m}}$ determine small changes in our housing heat index. Notice, however, that this finding is mostly driven by the assumption that $\lambda^{q}$ equals one. As $\lambda^{q}$ increases (decreases), the average gap between list prices and transaction prices should explain a larger (smaller) portion of the variability of $\hat{\theta}^{29}$

How do changes in $\hat{\kappa}^{d}$ affect the housing heat index? Our intuition suggests that in hot markets where sellers have most of the bargaining power, price discounts are generally not granted. One would thus expect that an increase in $\hat{\kappa}^{d}$ is associated with a lower index. A quick look at equation (26) reveals that the effects of $\hat{\kappa}^{d}$ on $\hat{\theta}$ may be ambiguous and may depend on sample moments. One could differentiate this equation in search of conditions required to guarantee that $\frac{\partial \hat{\theta}}{\partial \hat{\kappa}^{d}}<0$. Instead, we test if this implication holds in our sample. In the fifth (sixth) row of Table 5, we add (subtract) one standard deviation to $\hat{\kappa}^{d}$ and estimate $\hat{\theta}$ (while keeping the other variables constant at their sample means). Two observations are

\footnotetext{
${ }^{29}$ The assumption about the particular value of $\lambda^{q}$ does not change the qualitative nature of the results discussed in this section. Clearly, changes in $\lambda^{q}$ can affect the level of the index. However, index trends across time and differences in the index between geographic areas seem robust to the choice of $\lambda^{q}$. Researchers who want to give a higher (lower) "weight" to $\hat{\kappa}^{p_{s}}-\hat{\kappa}^{p_{m}}$ could choose larger (smaller) values of $\lambda^{q}$.
} 
worth discussing. First, given our sample moments, the index and $\hat{\kappa}^{d}$ have the expected and intuitive inverse relationship. Second, it seems that most of the variation of $\hat{\theta}$ is driven by changes in $\hat{\kappa}^{d}$. For instance, when the share of transactions that occurred below the list price increases by two standard deviations from 0.34 to $0.74, \hat{\theta}$ decreases from 0.83 to 0.49 . This variation is notably large considering that $\hat{\theta}$ ranges from 0.39 to 0.88 in our sample (Figure $5)$.

Finally, it is important to understand the relationship between $\hat{\kappa}^{T}$ and $\hat{\theta}$. Results shown in the bottom rows of Table 5 suggest that changes in time on the market have very little impact on the housing heat index. Even a two standard deviation change (from 76 to 21 days) brings almost no variation to $\hat{\theta}$. This finding is not the consequence of the particular discount rate $r$ used to calibrate the model. Even when a very large annual discount rate of $25 \%$ is chosen, the effects of $\hat{\kappa}^{T}$ on $\hat{\theta}$ seem to be minimal. Equation (26) also reveals a somewhat counter intuitive result: $\hat{\theta}$ increases with time on the market. This is a direct implication of the stationary and partial equilibrium nature of the theoretical model. Our model predicts that as sellers' bargaining power goes up so do prices; but the increase in prices is large enough to determine a longer marketing period. ${ }^{30}$ Thus, a note of caution should be added when interpreting our index: larger values of $\hat{\theta}$ are not necessarily associated with faster sales.

\subsection{Caveats and opportunities for future research}

We have illustrated the link between the coefficients of reduced-form hedonic equations and the structural parameters of a home seller's search model. To achieve this goal, however,

\footnotetext{
${ }^{30}$ Notice from equations (16) and (15) that sale rates decrease with $\theta$. This occurs because list and reservation prices increase with seller's bargaining power. However, as prices raise, the likelihood of a sale diminishes. As a result, the model implies that $\theta$ is positively associated with marketing time.
} 
we impose strong assumptions about the home seller search process. Perhaps the strongest assumption we have made is about stationarity. Stationarity allows us to find an analytical solution to the seller's search problem and simplify the estimation method. Unfortunately, this assumption imposes several restrictions to the data generating process that are likely rejected by the data in most housing markets. For example, stationarity implies that sellers' posting and reservation prices do not change with time which is not the case in our data: in our 2006 sample, about 40 percent of the observations dropped the initial list price before a sale was made. Further research is needed to understand the causes and consequences of list price changes. ${ }^{31}$

Another important caveat of our findings is related to sample selection. Because our model is not able to explain the fact that some sellers in the market withdraw their properties, we only analyze listings that end up in a sale. For instance, during 2006, about half of listings that were posted on the MLS ended up in a sale; the rest of listings either expire or are withdrawn from the market before a sale is made. Because our estimation method uses data from housing sales, it may be subject to sample selection biases. ${ }^{32}$

Notice, that the limitations discussed above are shared by most studies that use housing transaction data. Even simple housing price indices (such as the Federal Housing Finance Agency OFHEO price index) use transaction data without accounting for censored observa-

\footnotetext{
${ }^{31}$ De Wit and Van der Klaauw (2010) is one of the few papers in the literature that analyzes the effect of list price changes on time on the market.

${ }^{32}$ It is important to note that the fraction of listings that are sold changes with market conditions. For instance, out of all the listings that were posted on the MLS during 2003, about 83 percent ended up in a sale. On the other hand, the fraction of listings that were posted in 2007 and were ultimately sold was close to 46 percent. The rise in withdrawal rates in 2007 coincides with a sharp decrease in home prices. This is consistent with the findings of Genesove and Mayer and (2001) and Engelhardt (2003) who suggest that homeowners are loss-averse. If the marginal disutility of nominal losses is higher than the marginal utility of nominal gains, sellers should be reluctant to set a list price below the original posting price during a downturn in the market and prefer to withdraw the listing.
} 
tions. By presenting a candid discussion about the limitations of our approach we hope to motivate future work in this area.

\section{Conclusions}

This paper illustrates the relationship between the structural parameters of a home seller search model and the coefficients of four linear reduced-form equations that explain i) log list prices, ii) $\log$ sale prices, iii) the share of transactions below the list price and iv) marketing time. This approach is useful because it allows adding a very large set of covariates into the structural model and estimate its parameters at a low computational cost. More importantly, this method allows estimation of structural parameters using individual-level or aggregate data. Thus one can easily exploit readily available aggregate MLS data to construct indicators that measure housing market conditions.

The model is first estimated using individual-level housing transaction data and it is used to analyze the relationship between list prices and marketing time. Despite its simplicity, the model is able to replicate the data remarkably well. Counterfactual analysis makes the reasonable prediction that the effects of overpricing are large and non-linear. For instance, if the list price to expected price ratio increases by 1 (10) percentage point, the expected time on the market rises by about 10 (200) days.

Aggregate data from housing transactions are then used to compute a structural parameter that measures home sellers' bargaining power for each year in the period 1998-2009. Estimates suggest that sellers had most of the bargaining power between 2001 and 2006; in other years, the opposite is true. These trends are consistent with popular perceptions about the "heat" of the housing market in the area. The index can be computed for any other level 
of aggregation such as zip code or home type. Given the importance of the housing market and the availability of MLS (aggregate) data, the construction of such an index for different areas and on regular basis should be a relative straightforward task that could be relevant for the real estate industry and for regulators. It may be of interest to home buyers and sellers (and their agents) who generally like to be informed about their degree of bargaining power when setting their optimal marketing strategies. The "heat" of the housing market could also be relevant to investors and regulators because, to a certain extent, it provides information about market risk and liquidity, and it may even be a valuable input to predict future home prices.

We hope that our approach motivates the use of list prices and time on the market (in addition to sale prices) to systematically measure the performance of the housing market. Our work can provide a benchmark for future research and may be useful in other applications where (low budget) index numbers of housing market conditions are needed.

\section{Appendix 1}

Given our functional form assumptions $1-\phi\left(P_{s}, s\right)=\left[\frac{P_{s}}{s}\right]^{-\left(\lambda^{q}+\lambda^{s}\right)}, u\left(P_{s}, s\right)=\frac{1}{1-\alpha}\left[\frac{P_{s}}{s}\right]^{1-\alpha}$, and $u\left(R_{s}, s\right)=\frac{1}{1-\alpha}\left[\frac{R_{s}}{s}\right]^{1-\alpha}$. Then, equation (4) becomes

$$
\begin{aligned}
\frac{\left[\frac{P_{s}}{s}\right]^{1-\alpha}-\left[\frac{R_{s}}{s}\right]^{1-\alpha}}{(1-\alpha)\left[\frac{P_{s}}{s}\right]^{-\alpha}} & =\frac{\left[\frac{P_{s}}{s}\right]}{\left(\lambda^{q}+\lambda^{s}\right)} \\
\frac{1-\left[\frac{P_{s}}{R_{s}}\right]^{-(1-\alpha)}}{1-\alpha} & =\frac{1}{\lambda^{q}+\lambda^{s}} \\
1-e^{-(1-\alpha) \ln \left[\frac{P_{s}}{R_{s}}\right]} & =\frac{1-\alpha}{\lambda^{q}+\lambda^{s}} \\
-(1-\alpha) \ln \left[\frac{P_{s}}{R_{s}}\right] & =\ln \left\{1-\frac{1-\alpha}{\lambda^{q}+\lambda^{s}}\right\} \\
\ln \left[\frac{P_{s}}{R_{s}}\right] & =\frac{1}{(1-\alpha)} \ln \left\{\frac{\lambda^{q}+\lambda^{s}}{\lambda^{q}+\lambda^{s}-(1-\alpha)}\right\} .
\end{aligned}
$$


Similarly, equation (5) becomes

$$
\begin{aligned}
& \frac{1}{1-\alpha}\left[\frac{R_{s}}{s}\right]^{1-\alpha}= \beta \theta \frac{1}{1-\alpha}\left[\frac{P_{s}}{s}\right]^{-\left(\lambda^{q}+\lambda^{s}\right)+(1-\alpha)} \\
&+\beta\left(1-\theta\left[\frac{P_{s}}{s}\right]^{-\left(\lambda^{q}+\lambda^{s}\right)}\right) \frac{1}{1-\alpha}\left[\frac{R_{s}}{s}\right]^{1-\alpha} \\
& \frac{1-\beta}{\beta}\left[\frac{R_{s}}{s}\right]^{1-\alpha}= \theta\left[\frac{P_{s}}{s}\right]^{-\left(\lambda^{q}+\lambda^{s}\right)+(1-\alpha)}-\theta\left[\frac{P_{s}}{s}\right]^{-\left(\lambda^{q}+\lambda^{s}\right)}\left[\frac{R_{s}}{s}\right]^{1-\alpha} \\
& \frac{r}{\theta} e^{(1-\alpha) \ln \left[\frac{R_{s}}{s}\right]}=e^{\left[-\left(\lambda^{q}+\lambda^{s}\right)+(1-\alpha)\right] \ln \left[\frac{P_{s}}{s}\right]}-e^{-\left(\lambda^{q}+\lambda^{s}\right) \ln \left[\frac{P_{s}}{s}\right]+(1-\alpha) \ln \left[\frac{R_{s}}{s}\right]} \\
& \frac{r}{\theta} e^{(1-\alpha) \ln \left[\frac{R_{s}}{s}\right]+\left[\left(\lambda^{q}+\lambda^{s}\right)-(1-\alpha)\right] \ln \left[\frac{P_{s}}{s}\right]}=1-e^{(1-\alpha) \ln \left[\frac{R_{s}}{s}\right]-(1-\alpha) \ln \left[\frac{P_{s}}{s}\right]} \\
& \frac{r}{\theta} e^{-(1-\alpha) \ln \left[\frac{P_{s}}{R s}\right]+\left(\lambda^{q}+\lambda^{s}\right) \ln \left[\frac{P_{s}}{s}\right]}=1-e^{-(1-\alpha) \ln \left[\frac{P_{s}}{R_{s}}\right]} .
\end{aligned}
$$

We substitute (28) in the previous expression and obtain that

$$
\frac{r}{\theta}\left[1-\frac{1-\alpha}{\lambda^{q}+\lambda^{s}}\right] e^{\left(\lambda^{q}+\lambda^{s}\right) \ln \left[\frac{P_{s}}{s}\right]}=\frac{1-\alpha}{\lambda^{q}+\lambda^{s}} .
$$

Then, we solve for

$$
\begin{aligned}
\ln \left[\frac{P_{s}}{s}\right] & =\frac{1}{\lambda^{q}+\lambda^{s}} \ln \left\{\frac{\theta}{r} \frac{1-\alpha}{\left(\lambda^{q}+\lambda^{s}-(1-\alpha)\right)}\right\} \\
P_{s} & =s\left\{\frac{\theta}{r} \frac{1-\alpha}{\left(\lambda^{q}+\lambda^{s}-(1-\alpha)\right)}\right\}^{\frac{1}{\lambda^{q}+\lambda^{s}}} .
\end{aligned}
$$

Finally, equation (29) is used to find $R_{s}$.

\section{Appendix 2}

Let $\hat{\kappa}^{p_{s}}, \hat{\kappa}^{p_{m}}, \hat{\kappa}^{d}$, and $\hat{\kappa}^{T}$ be the constant terms of the (reduced-form) moment conditions 1, 2, 3 and 4, respectively. From equations (18) and (19), it is clear that

$$
\hat{\kappa}^{p_{s}}=\hat{\delta}^{0}+\frac{1}{\lambda^{q}+\hat{\lambda}^{s}} \ln \left\{\frac{\hat{\theta}}{r} \frac{1-\hat{\alpha}}{\left(\lambda^{q}+\hat{\lambda}^{s}-(1-\hat{\alpha})\right)}\right\}
$$


and

$$
\begin{aligned}
\hat{\kappa}^{p_{m}}= & \hat{\delta}^{0}+\frac{1}{\lambda^{q}+\hat{\lambda}^{s}} \ln \left\{\frac{\hat{\theta}}{r} \frac{1-\hat{\alpha}}{\left(\lambda^{q}+\hat{\lambda}^{s}-(1-\hat{\alpha})\right)}\right\} \\
& -\frac{1-\hat{\tilde{\theta}}}{1-\hat{\alpha}} \ln \left\{\frac{\lambda^{q}+\hat{\lambda}^{s}}{\lambda^{q}+\hat{\lambda}^{s}-(1-\hat{\alpha})}\right\} .
\end{aligned}
$$

Subtracting these two equations it is found that

$$
\frac{\hat{\kappa}^{p_{s}}-\hat{\kappa}^{p_{m}}}{\hat{\kappa}^{d}}=\frac{1}{1-\hat{\alpha}} \ln \left\{\frac{\lambda^{q}+\hat{\lambda}^{s}}{\lambda^{q}+\hat{\lambda}^{s}-(1-\hat{\alpha})}\right\},
$$

where $\hat{\kappa}^{d}$ has been used to estimate $1-\tilde{\theta}\left(\hat{\kappa}^{d}=1-\widehat{\tilde{\theta}}\right)$. Notice that one can use the definition of $\tilde{\theta}$ to find that

$$
\begin{aligned}
1-\hat{\kappa}^{d} & =\widehat{\tilde{\theta}} \\
& =\frac{\hat{\theta} \widehat{\operatorname{Pr}}\left\{\operatorname{trade} \mid P=P_{s}^{*}\right\}}{\widehat{\operatorname{Pr}}\{\operatorname{trade}\}} \\
& =\frac{\hat{\theta} \frac{r}{\hat{\theta}} \frac{\left(\lambda^{q}+\hat{\lambda}^{s}-(1-\hat{\alpha})\right)}{1-\hat{\alpha}}}{\widehat{\operatorname{Pr}}\{\operatorname{trade}\}} \\
& =\frac{r \frac{\left(\lambda^{q}+\hat{\lambda}^{s}-(1-\hat{\alpha})\right)}{1-\hat{\alpha}}}{1 / \hat{\kappa}^{T}},
\end{aligned}
$$

where we have used equation (15) to compute $\widehat{\operatorname{Pr}}\left\{\right.$ trade $\left.\mid P=P_{s}^{*}\right\}$ and the properties of the geometric distribution to estimate the unconditional probability that trades occurs (that is, $\widehat{\operatorname{Pr}}\{$ trade $\left.\}=1 / \hat{\kappa}^{T}\right)$. After some manipulation, we obtain that

$$
\lambda^{q}+\hat{\lambda}^{s}=(1-\hat{\alpha})\left(1+\frac{1-\hat{\kappa}^{d}}{\hat{\kappa}^{T} r}\right) .
$$

After replacing (32) into (30) it is found that

$$
\begin{aligned}
1-\hat{\alpha} & =\frac{\hat{\kappa}^{d}}{\hat{\kappa}^{p_{s}}-\hat{\kappa}^{p_{m}}} \ln \left\{\frac{\hat{\kappa}^{T} r+\left(1-\hat{\kappa}^{d}\right)}{1-\hat{\kappa}^{d}}\right\} \\
\hat{\alpha} & =1-\frac{\hat{\kappa}^{d}}{\hat{\kappa}^{p_{s}}-\hat{\kappa}^{p_{m}}} \ln \left\{1+\frac{\hat{\kappa}^{T} r}{1-\hat{\kappa}^{d}}\right\} .
\end{aligned}
$$


Let us now use the fourth moment condition

$$
\hat{\kappa}^{T}=\frac{1}{\hat{\theta} \widehat{\operatorname{Pr}}\left\{\text { trade } \mid P=P_{s}^{*}\right\}+(1-\hat{\theta}) \widehat{\operatorname{Pr}}\left\{\text { trade } \mid P=R_{s}^{*}\right\}} .
$$

Notice from (31) that $\hat{\theta} \widehat{\operatorname{Pr}}\left\{\right.$ trade $\left.\mid P=P_{s}^{*}\right\}=\left(1-\hat{\kappa}^{d}\right) / \hat{\kappa}^{T}$. Also note that

$$
\begin{aligned}
\widehat{\operatorname{Pr}}\{\text { trade } \mid P & \left.=R_{s}^{*}\right\}=\left[\frac{r}{\hat{\theta}} \frac{\left(\lambda^{q}+\hat{\lambda}^{s}-(1-\hat{\alpha})\right)}{1-\hat{\alpha}} \cdot\left(\frac{\lambda^{q}+\hat{\lambda}^{s}}{\lambda^{q}+\hat{\lambda}^{s}-(1-\hat{\alpha})}\right)^{\frac{\hat{\lambda}^{s}}{1-\hat{\alpha}}}\right] \\
& =\left[\frac{1}{\hat{\theta}}\left\{r \frac{\left(\lambda^{q}+\hat{\lambda}^{s}-(1-\hat{\alpha})\right)}{1-\hat{\alpha}}\right\} \cdot \exp \left\{\frac{\hat{\lambda}^{s}}{1-\hat{\alpha}} \ln \left(\frac{\lambda^{q}+\hat{\lambda}^{s}}{\lambda^{q}+\hat{\lambda}^{s}-(1-\hat{\alpha})}\right)\right\}\right] \\
& =\left[\frac{1}{\hat{\theta}}\left\{\frac{1-\hat{\kappa}^{d}}{\hat{\kappa}^{T}}\right\} \cdot \exp \left\{\hat{\lambda}^{s} \frac{\hat{\kappa}^{p_{s}}-\hat{\kappa}^{p_{m}}}{\hat{\kappa}^{d}}\right\}\right] .
\end{aligned}
$$

We replace this into $(33)$

$$
\hat{\kappa}^{T}=\frac{1}{\left(1-\hat{\kappa}^{d}\right) / \hat{\kappa}^{T}+\frac{(1-\hat{\theta})}{\hat{\theta}}\left\{\frac{1-\hat{\kappa}^{d}}{\hat{\kappa}^{T}}\right\} \cdot \exp \left\{\hat{\lambda}^{s} \frac{\hat{\kappa}^{p_{s}}-\hat{\kappa}^{p_{m}}}{\hat{\kappa}^{d}}\right\}}
$$

and solve for $\hat{\theta}$

$$
\hat{\theta}=\frac{1}{1+\left(\frac{\hat{\kappa}^{d}}{1-\hat{\kappa}^{d}} \exp \left\{-\hat{\lambda}^{s} \frac{\hat{\kappa}^{p_{s}}-\hat{\kappa}^{p_{m}}}{\hat{\kappa}^{d}}\right\}\right)} .
$$

We now have enough information to derive

$$
\hat{\delta}^{0}=\hat{\kappa}^{p_{s}}-\frac{1}{\lambda^{q}+\hat{\lambda}^{s}} \ln \left\{\frac{\hat{\theta}}{r} \frac{1-\hat{\alpha}}{\left(\lambda^{q}+\hat{\lambda}^{s}-(1-\hat{\alpha})\right)}\right\} .
$$

\section{References}

[1] Albrecht, J., Gautier, P., and Vroman, S. 2010. Directed Search in the Housing Market. Working paper. Georgetown University.

[2] Allen, M., R. Rutherford and T. Thomson. 2009. Residential Asking Rents and Time on the Market. Journal of Real Estate Finance and Economics 38: 351-365. 
[3] Anglin, P., R. Rutherford, and T. Springer. 2003. The Trade-off Between the Selling Price of Residential Properties and Time-on-the-Market: The Impact of Price Setting. Journal of Real Estate Finance and Economics 26: 95-111.

[4] Arnold, M. 1999. Search, Bargaining and Optimal Asking Prices. Real Estate Economics 27: $453-481$.

[5] Albrecht, J., A. Anderson, E. Smith, and S. Vroman. 2007. Opportunistic Matching in the Housing Market. International Economic Review 48: 641-664.

[6] Belkin, J., D. J. Hempel and D. W. Mcleavey. 1976. An Empirical Study of Time on Market Using Multidimensional Segmentation of Housing Markets. Journal of the American Real Estate and Urban Economics Association 4: 57-79.

[7] Carrillo, P. forthcoming. An Empirical Stationary Equilibrium Search Model of the Housing Market. International Economic Review.

[8] Carrillo, P., and J. Pope. 2012. Are homes hot or cold potatoes? The distribution of marketing time in the housing market. Regional Science and Urban Economics 42: $189-197$.

[9] Chen, Y., and R. Rosenthal. 1996a. Asking Prices as Commitment Devices. International Economic Review 37: 129-55.

[10] Chen, Y., and R. Rosenthal. 1996b. On the Use of Ceiling-Price Commitments by Monopolists. RAND Journal of Economics 27: 207-20. 
[11] De Wit, R. and B. van der Klaauw. 2010. Asymmetric Information and List Price Reductions in the Housing Market. CEPR Discussion Papers No 7799.

[12] Engelhardt, G.V. 2003. Nominal loss aversion, housing equity constraints, and household mobility: evidence from the United States. Journal of Urban Economics 53: 171-19.

[13] Forgey F., R. Rutherford and T. Springer. 1996. Search and Liquidity in Single-Family Housing. Real Estate Economics 3: 273-292.

[14] Genesove, D. and C. Mayer. 1997. Equity and Time to Sale in the Real Estate Market. The American Economic Review 87: 255-269.

[15] Genesove, D. and C. Mayer. 2001. Loss aversion and selling behavior: evidence from the housing market. Quarterly Journal of Economics 116: 1233-1260.

[16] Glower, M., D. Haurin, and P. Hendershott. 1998. Selling Time and Selling Price: The Influence of Seller Motivation. Journal of the American Real Estate and Urban Economics Association 26: 719-740.

[17] Han, L. and W. Strange. 2011. Bidding Wars for Houses. Working Paper. University of Toronto.

[18] Harding, J., S. Rosenthal and C.F. Sirmans. 2003. Estimating Bargaining Power in the Market for Existing Homes. The Review of Economics and Statistics 85: 178 - 188.

[19] Haurin, D. 1998. The Duration of Marketing Time of Residential Housing. AREUEA 16: $396-410$. 
[20] Haurin, D., J. Haurin, T. Nadauld and A. Sanders. 2010. List Prices, Sale Prices and Marketing Time: An Application to U.S. Housing Markets. Real Estate Economics 38: $659-685$.

[21] Horowitz, J. 1992. The Role of the List Price in Housing Markets: Theory and an Econometric Model. Journal of Applied Econometrics 2: 115-129.

[22] Huang, J. and R. B. Palmquist. 2001. Environmental Conditions, Reservation Prices, and Time on the Market for Housing. The Journal of Real Estate Finance and Economics 22: $203-219$.

[23] Kang, H. and M. Gardner. 1989. Selling Price and Marketing Time in Residential Real Estate Market. The Journal of Real Estate Research 4: 21-35.

[24] Knight, J. 2002. Listing Time, Time on Market, and Ultimate Selling Price: Causes and Effects of Listing Price Changes. Real Estate Economics 30: 213-237.

[25] Lippman, S., and J. McCall. 1976. The Economics of Job Search: A Survey. Parts I and II, Economic Inquiry 14: 155-189 and 347-368.

[26] Merlo, A. and F. Ortalo-Magne. 2004. Bargaining over Residential Real Estate: Evidence from England. Journal of Urban Economics 56: 192-216.

[27] Novy-Marx. 2009. Hot and Cold Markets. Real Estate Economics 37: 1-22.

[28] Sirmans, C.F., G.K. Turnbull and J.D. Benjamin. 1991. The Markets for Housing and Real Estate Broker Services. Journal of Housing Economics 1: 207-217. 
[29] Springer, T. 1996. Single-Family Housing Transactions: Seller Motivations, Price, and Marketing Time. Journal of Real Estate Finance and Economics 13: 237-54.

[30] Turnbull, G.K. and J. Dombrow. 2006. Spatial Competition and Shopping Externalities: Evidence from the Housing Market. The Journal of Real Estate Finance and Economics 32: $391-408$.

[31] Turnbull, G.K., C.F. Sirmans and J.D. Benjamin. 1990. Do Corporations Sell Houses for Less? A Test of Housing Market Efficiency. Applied Economics 66: 555-578.

[32] Turnbull G.K., J. Dombrow and C.F. Sirmans. 2006. Big House, Little House: Relative Size and Value. Real Estate Economics 34: 439-456.

[33] Turnbull, G. and V. Zahirovic-Herber. 2011. Why Do Vacant Houses Sell for Less: Holding Costs, Bargaining Power or Stigma? Real Estate Economics 39: 19-43.

[34] Yavas, A. 1992. A Simple Search and bargaining Model of Real Estate Markets. Journal of the American Real Estate and Urban Economics Association 20: 533-548.

[35] Yavas, A. and S. Yang. 1995. The Strategic Role of Listing Price in Marketing Real Estate: Theory and Evidence. Real Estate Economics 23: 347-368.

[36] Yinger, J. 1981. A Search Model of Real Estate Broker Behavior. American Economic Review 71: 591-605. 


\section{Table 1: Description of Variables}

\begin{tabular}{ll}
\multicolumn{1}{c}{ Variable } & \\
\hline & \\
Ps & Listing price in thousands \$ \\
Pm & Sale price in thousands \$ \\
DOM & Days on the market \\
Ps $>$ Pm & Equals one if listing price is greater that the transaction price \\
& \\
Sqft & Living area square feet \\
Acreage & Lot acreage \\
Bedrooms & Number of bedrooms \\
Full Bathrooms & Number of full bathrooms \\
Half Bathrooms & Number of half bathrooms \\
Basement & Equals one if unit has a basement and zero otherwise \\
Central & Equals one if unit has central heating and zero otherwise \\
Fireplace & Number of fireplaces \\
New & Equals one if unit is new and zero otherwise \\
Age & Age of the unit (in years) \\
HOA & Equals one if property has a home ownership association and zero otherwise \\
Detached & Equals one if unit is a detached single family home \\
Townhome & Equals one if unit is a townhome \\
&
\end{tabular}

Notes: Table shows shows a list of the variables used to estimate the empirical models 
Table 2: Descriptive Statistics

\begin{tabular}{|c|c|c|c|c|}
\hline Variable & Mean & St. Dev. & Min & Max \\
\hline \multicolumn{5}{|l|}{ Transaction } \\
\hline List price & 555.8 & 266.2 & 125.0 & $2,650.0$ \\
\hline Sale price & 528.4 & 244.5 & 125.0 & $1,995.0$ \\
\hline Days on the market & 54.9 & 53.2 & 1.0 & 391.0 \\
\hline Equals one if Ps > Pm & 0.73 & 0.44 & 0.0 & 1.0 \\
\hline \multicolumn{5}{|l|}{ Unit } \\
\hline Sqft & $1,709.3$ & 834.4 & 426.0 & $9,590.0$ \\
\hline Acreage & 0.21 & 0.46 & 0.0 & 8.6 \\
\hline Bedrooms & 3.30 & 1.07 & 0.0 & 13.0 \\
\hline Full Bathrooms & 2.29 & 0.83 & 1.0 & 8.0 \\
\hline Half Bathrooms & 0.77 & 0.64 & 0.0 & 11.0 \\
\hline Basement & 0.69 & 0.46 & 0.0 & 1.0 \\
\hline Central & 0.94 & 0.24 & 0.0 & 1.0 \\
\hline Fireplace & 0.90 & 0.71 & 0.0 & 5.0 \\
\hline New & 0.02 & 0.15 & 0.0 & 1.0 \\
\hline Age & 25.8 & 15.3 & 0.0 & 136.0 \\
\hline $\mathrm{HOA}$ & 0.61 & 0.49 & 0.0 & 1.0 \\
\hline Detached & 0.45 & 0.50 & 0.0 & 1.0 \\
\hline Townhome & 0.38 & 0.49 & 0.0 & 1.0 \\
\hline \multicolumn{5}{|l|}{ Neighborhood } \\
\hline Density & 20.9 & 21.5 & 0.2 & 237.5 \\
\hline Black & 0.08 & 0.09 & 0.0 & 0.9 \\
\hline Hispanic & 0.10 & 0.09 & 0.0 & 0.7 \\
\hline Greater than 65 & 0.08 & 0.06 & 0.0 & 0.5 \\
\hline HS dropouts & 0.08 & 0.08 & 0.0 & 0.7 \\
\hline Unemployment & 0.02 & 0.02 & 0.0 & 0.2 \\
\hline Income & 85.9 & 28.2 & 14.5 & 200.0 \\
\hline Observations & 14 & & & \\
\hline
\end{tabular}

Notes: Table shows shows descriptive statistics of the variables used to estimate the empirical models. The data correspond to residential real estate transactions in Fairfax County, VA, that were listed on the local MLS between January and December 2006 and sold before July 2007. 


\section{Table 3a. Structural Parameters}

$\begin{array}{rr}\alpha & \\ \alpha & 0.522 \\ \lambda^{\mathrm{q}}+\lambda^{\mathrm{s}} & 15.970 \\ \theta & 0.485 \\ \sigma^{\mathrm{u}} & 0.105\end{array}$

Note: Table displays estimates of structural model parameters using housing transaction data from Fairfax

County in 2006 . We normalize the annual discount rate to

0.04 and $\lambda^{\mathrm{q}}=1$. Standard errors (not shown) can be computed using the delta method. All coefficients are significant at the $1 \%$ level. 


\section{Table 3b. Structural Coefficients of $\ln (s)$ and OLS}

(1)

$\ln (s)$

Structural estimates of

$\delta^{0}$

Constant

Log square footage

Acreage

Bedrooms

Full Bathrooms

Half Bathrooms

Basement

Central

One fireplace

More than one fireplace

New

Age

Age $^{2}$

HOA

Detached

Townhome

Density

Black

Hispanic

Greater than 65

HS dropouts

Unemployment

Log median household income

Dummies for Month/Year (11)

Dummies for Census Tracts (175)

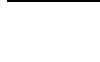

1.876

$$
0.341
$$

0.077

0.026

0.046

0.013

0.063

$-0.002$

0.025

0.071

0.009

$-0.010$

0.0001

0.003

0.367

0.154

$-0.0002$

$-0.131$

0.059

0.247

0.022

$-0.040$

0.088

Yes

Yes
(2)

OLS Dependent variable is the log of transaction prices

prices

$\begin{aligned} 2.199 & (0.265) * * * \\ 0.334 & (0.012) * * * \\ 0.072 & (0.012)^{* * *} \\ 0.028 & (0.003)^{* * *} \\ 0.045 & (0.003)^{* * *} \\ 0.012 & (0.004)^{* * *} \\ 0.064 & (0.005)^{* * *} \\ -0.001 & (0.004) \\ 0.025 & (0.005)^{* * *} \\ 0.070 & (0.007)^{* * *} \\ 0.030 & (0.020) \\ -0.010 & (0.001)^{* * *} \\ 0.0001 & (0.000)^{* * *} \\ 0.002 & (0.004) \\ 0.368 & (0.014)^{* * *} \\ 0.160 & (0.010)^{* * *}\end{aligned}$

$-0.0004 \quad(0.005)$

$-0.125 \quad(0.055) * *$

$0.061 \quad(0.050)$

$0.243 \quad(0.078) * * *$

$0.032 \quad(0.071)$

$-0.047 \quad(0.187)$

$0.088 \quad(0.020) * * *$

R square

Number of observations

14,182

Yes

Yes

\begin{tabular}{c} 
Yes \\
Yes \\
\hline 0.933 \\
14,182 \\
\hline
\end{tabular}

Notes: Column (1) displays estimates of structural model parameters. Model has been estimated using housing transaction data from Fairfax County in 2006 . We normalize the annual discount rate to 0.04 and $\lambda^{\mathrm{q}}=1$.

Column (2) displays coefficients of a hedonic regression. Standard errors clustered at the census block-group level are shown in parenthesis. *, **, ***, denote significance at the 10,5 , and 1 percent level, respectively. 


\section{Table 4a. Within Sample Fit: Means}

\begin{tabular}{lcrr} 
& & \multicolumn{2}{c}{ Mean } \\
\cline { 1 - 1 } Vist price (\$ thousands) & & 555.81 & 551.41 \\
Sale price (\$ thousands) & & 528.36 & 526.53 \\
Days on market & & 54.93 & 54.71
\end{tabular}

Note: First column of Table shows average list price, sale price and marketing time using the Fairfax County, VA, 2006 sample. We use the estimated structural model to simulate housing transactions and compute average list price, sale price and days on the market. Averages of simulated data are displayed in the second column.

\section{Table 4b. Within Sample Fit: Marketing Time C.D.F.}

$\begin{array}{rrrr} & & \text { Actual } & \text { Predicted } \\ \text { Percentile } & 1 & 3 \\ \text { 5th } & 6 & 6 \\ \text { 10th } & 15 & 16 \\ \text { 25th } & 38 & 38 \\ 50 \text { th } & 78 & 76 \\ \text { 75th } & 127 & 124 \\ \text { 90th } & 164 & 161 \\ \text { 95th } & & \end{array}$

Note: To simulate time on the market, we first use the structural parameters of the model to construct $\omega$, the unconditional per-period probability of trade. Then, for each property and every period $t$ we draw an independent realization of a standard uniform random variable, $u$. If $u$ is less than $\omega$, then trade occurs at period $t$; $o$ therwise, the seller stays on the market for another period. We repeat this procedure until every unit in our sample has been sold. 


\section{Table 5. Determinants of Seller's Bargaining Power}

\begin{tabular}{|c|c|c|c|c|}
\hline & \multicolumn{3}{|c|}{ Inputs for $\theta$} & \multirow[b]{2}{*}{$\theta\left(\mathrm{k}^{\mathrm{ps}}-\mathrm{k}^{\mathrm{pm}} ; \mathrm{k}^{\mathrm{d}} ; \mathrm{k}^{\mathrm{T}}\right)$} \\
\hline & $\mathrm{k}^{\mathrm{ps}}-\mathrm{k}^{\mathrm{pm}}$ & $k^{\mathrm{d}}$ & $\mathrm{k}^{\mathrm{T}}$ & \\
\hline Mean (1997 - 2009) & 0.025 & 0.537 & 48.34 & 0.692 \\
\hline Standard error (SE) & 0.024 & 0.199 & 27.74 & \\
\hline Adding one SE to [ $\left.\mathrm{k}^{\mathrm{ps}}-\mathrm{k}^{\mathrm{pm}}\right]$ & 0.049 & 0.537 & 48.34 & 0.683 \\
\hline Substracting one SE to $\left[\mathrm{k}^{\mathrm{ps}}-\mathrm{k}^{\mathrm{pm}}\right]$ & 0.001 & 0.537 & 48.34 & 0.702 \\
\hline Adding one SE to $\mathrm{k}^{\mathrm{d}}$ & 0.025 & 0.736 & 48.34 & 0.487 \\
\hline Substracting one SE to $\mathrm{k}^{\mathrm{d}}$ & 0.025 & 0.338 & 48.34 & 0.833 \\
\hline Adding one $\mathrm{SE}$ to $\mathrm{k}^{\mathrm{T}}$ & 0.025 & 0.537 & 76.08 & 0.693 \\
\hline Substracting one SE to $\mathrm{k}^{\mathrm{T}}$ & 0.025 & 0.537 & 20.60 & 0.692 \\
\hline
\end{tabular}

Note: This Table shows how seller's bargaining power $\theta$ varies when the sample means $\mathrm{k}^{\mathrm{ps}}-\mathrm{k}^{\mathrm{pm}}, \mathrm{k}^{\mathrm{d}}$ and $\mathrm{k}^{\mathrm{T}}$ change by one standard deviation. The first three columns show the values at which $\theta$ is evaluated. In the fourth column, equation (26) is used to estimate $\theta$. 
Figure 1

Mean List and Sale Price

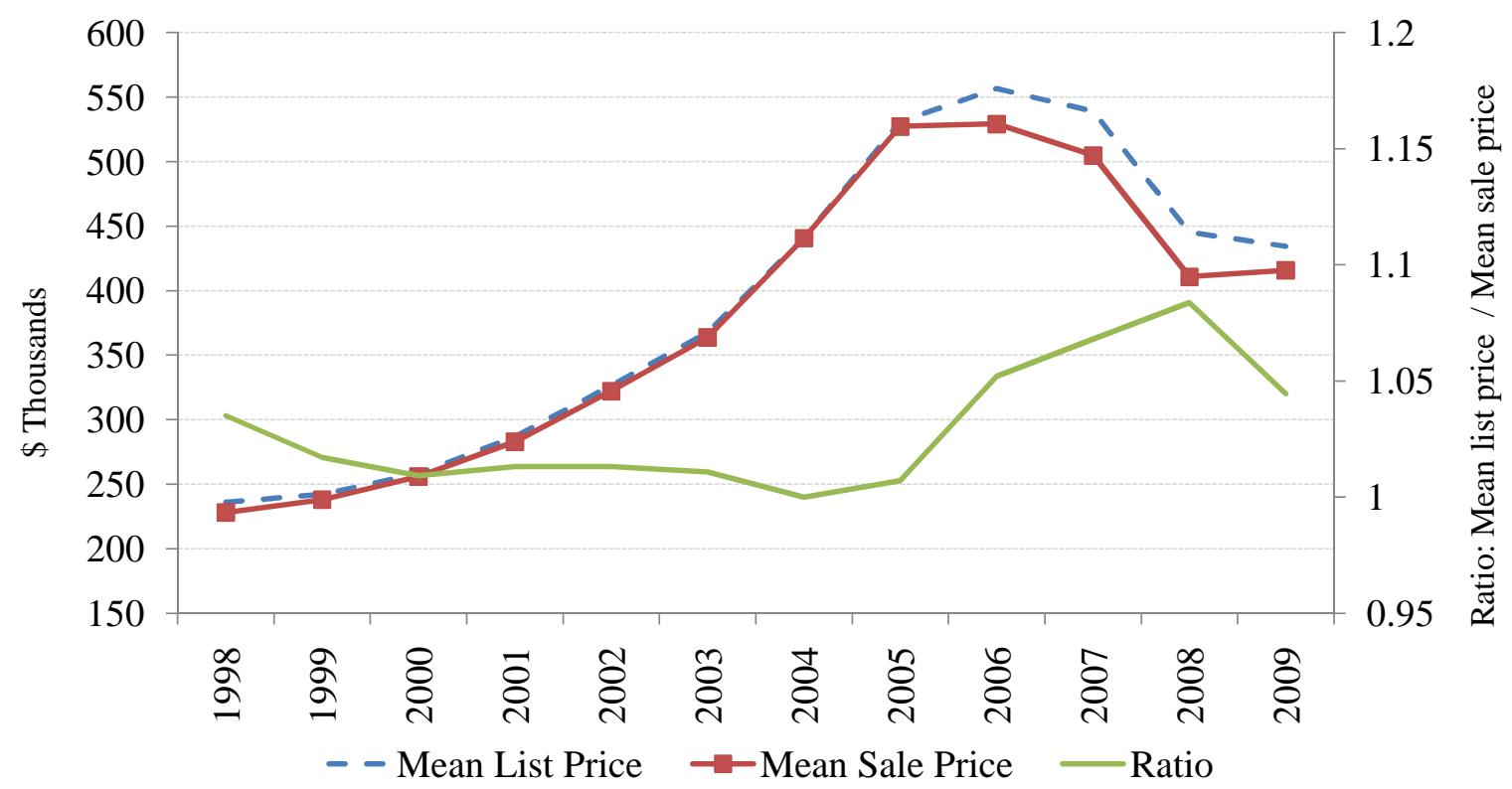

Note: Figure shows aggregate statistics of the Fairfax County, VA, housing market between 1998 and 2009. Statistics are computed using MLS data.

Figure 2

\section{Marketing Time and Price Discounts}

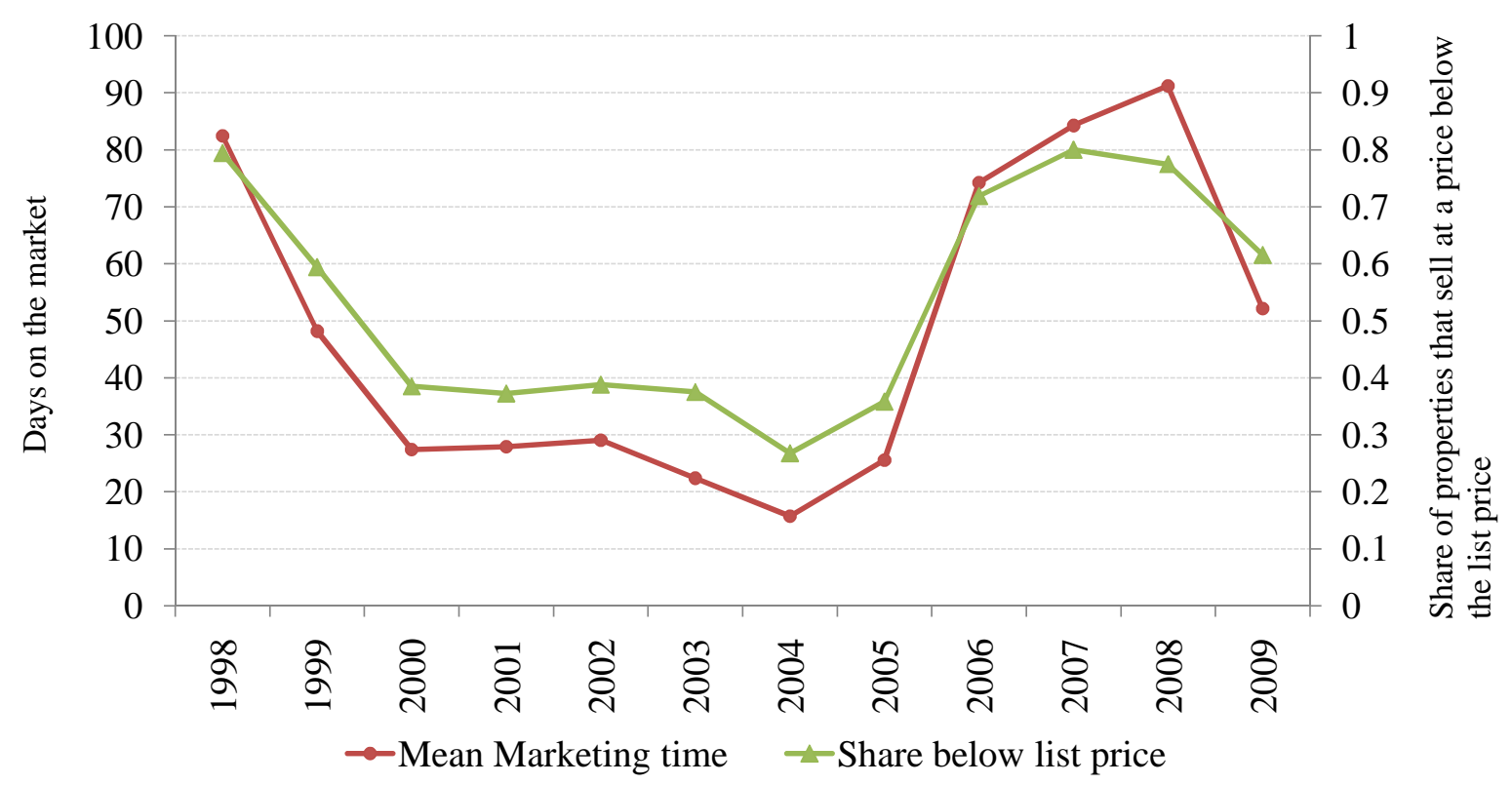

Note: Figure shows aggregate statistics of the Fairfax County, VA, housing market between 1998 and 2009. Statistics are computed using MLS data. 


\section{Figure 3}

Distribution of Marketing Time

Actual vs. Predicted Empirical C.D.F.

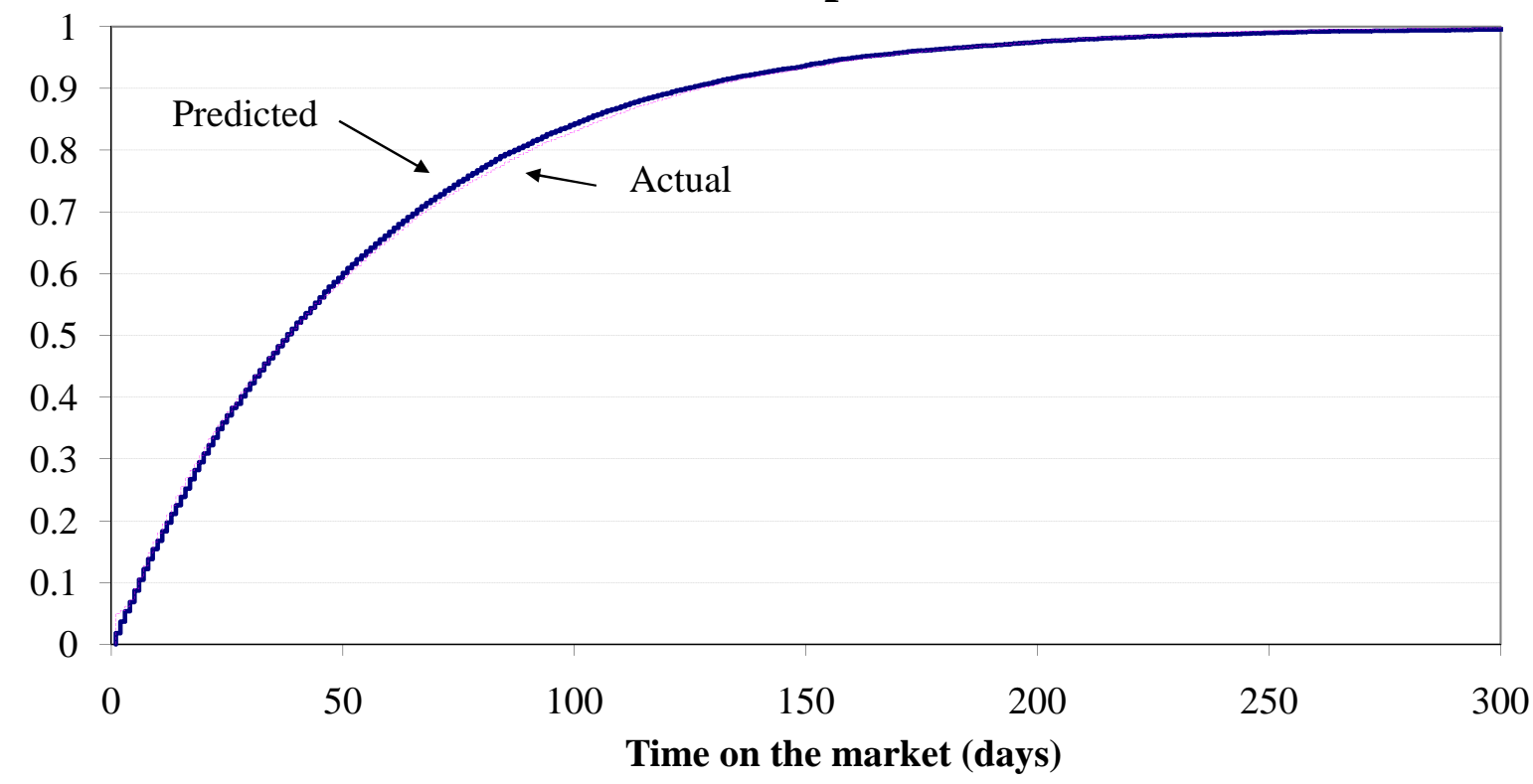

Note: This Figure compares the empirical cumulative distribution function of time on the market in the Fairfax County, VA, 2006 sample with the empirical distribution of the simulated data. To simulate time on the market, we use the estimated structural model.

\section{Figure 4}

\section{List Price and Time on the Market of Average Unit}

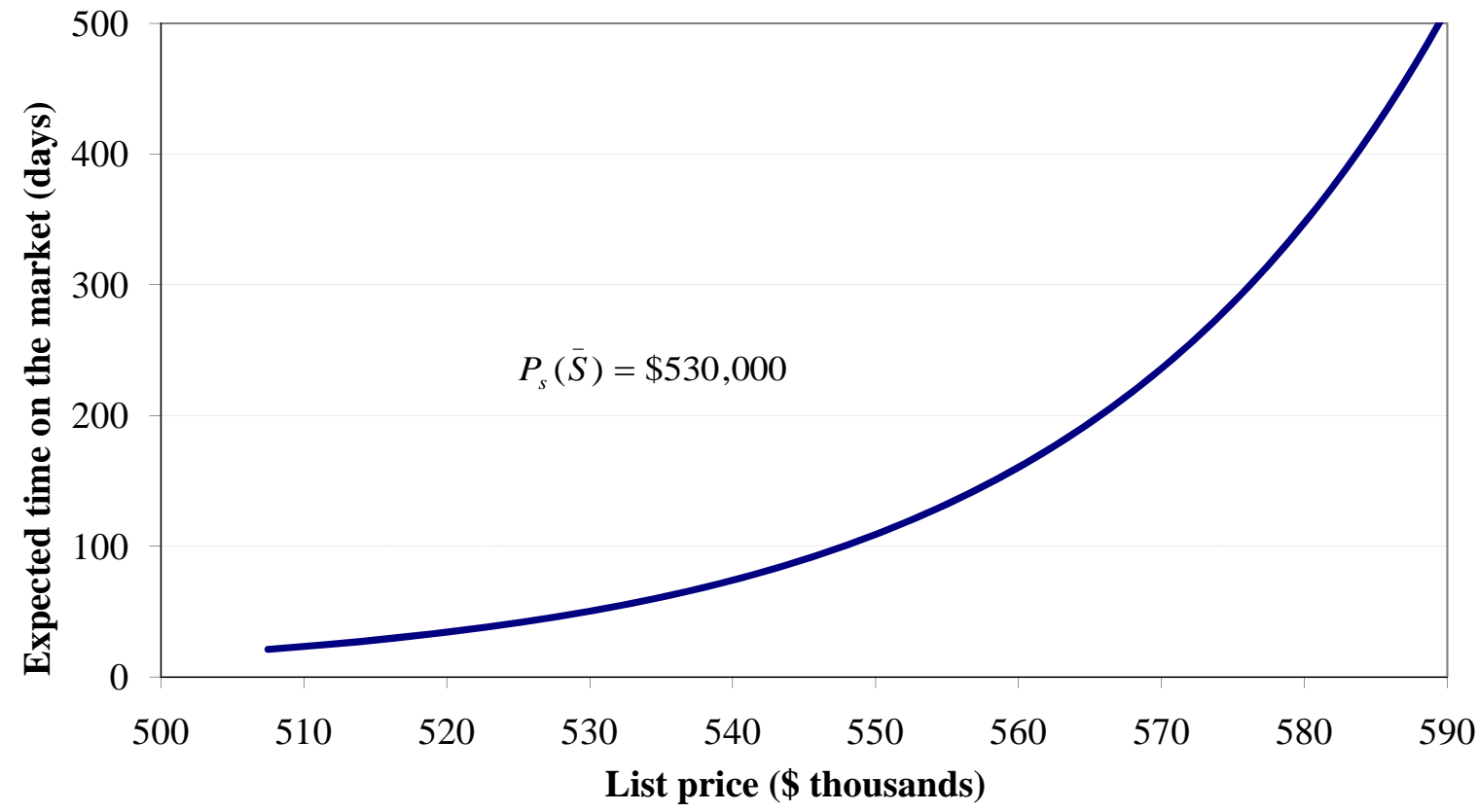

Note: This Figure shows the effects of list price on expected marketing. The list price of a typical unit (with average characteristics) is $\$ 530,000$. It takes about 55 days for this typical unit to sell. When the list price increases by 1 percentage point, the expected time on the market rises by about 10 days; if the list price raises by 10 percentage points, however, marketing time is expected to increase by approximately 200 days. 
Figure 5

Seller's Bargaining Power

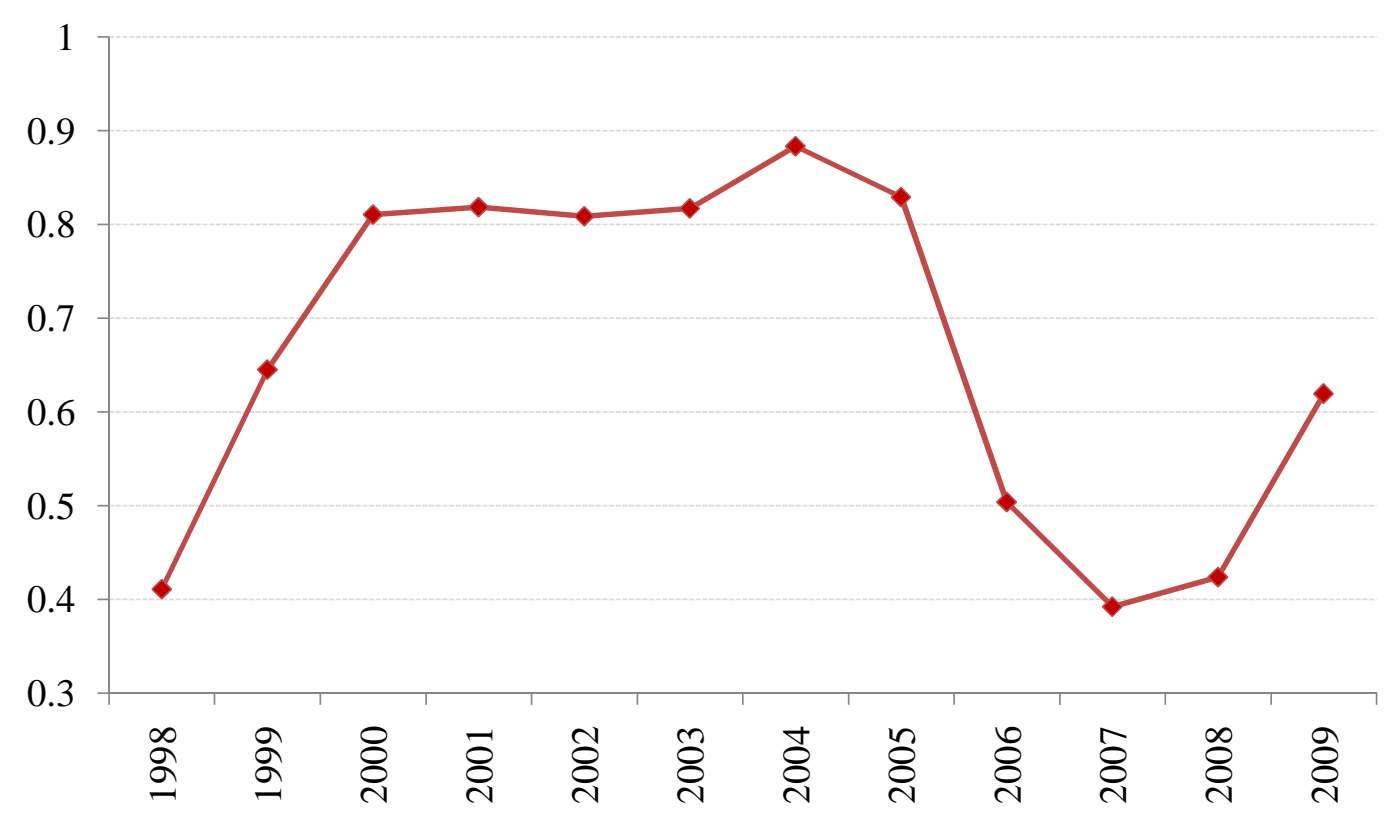

Note: Seller's bargaining power has been computed using equation (26) and aggregate annual data from Fairfax County, VA.

\section{Figure 6}

\section{Seller's Bargaining Power by Zip Code}

\section{Fairfax County, 2006}

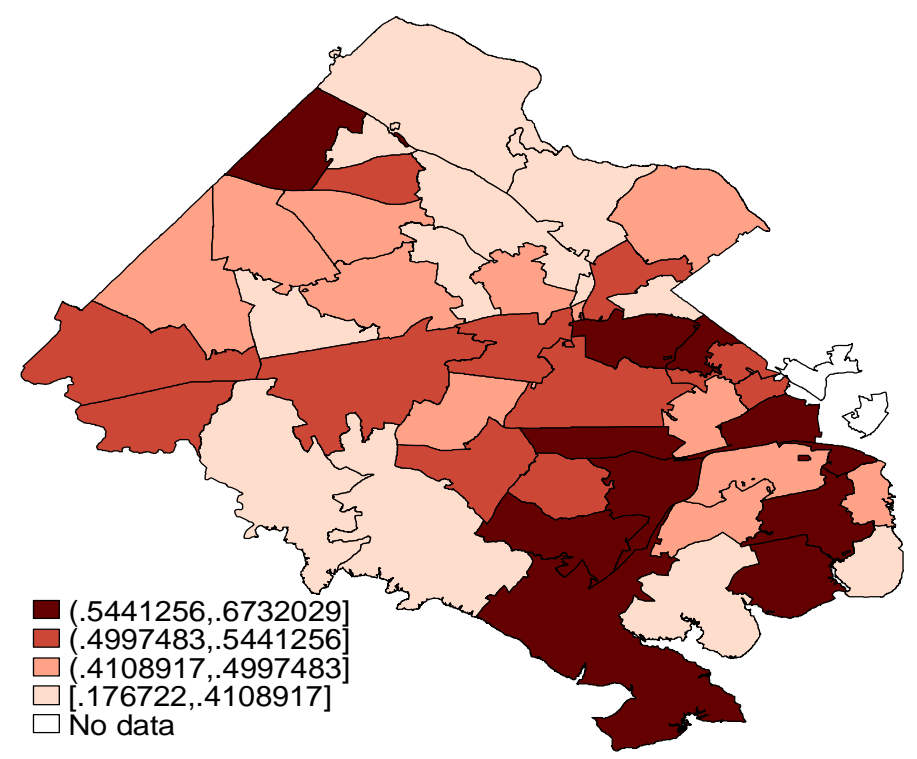

Note: Seller's bargaining power has been computed using equation (26) and aggregate annual data from Fairfax County, VA. 
Figure 7

\section{Seller's Bargaining Power by Type of Dwelling}

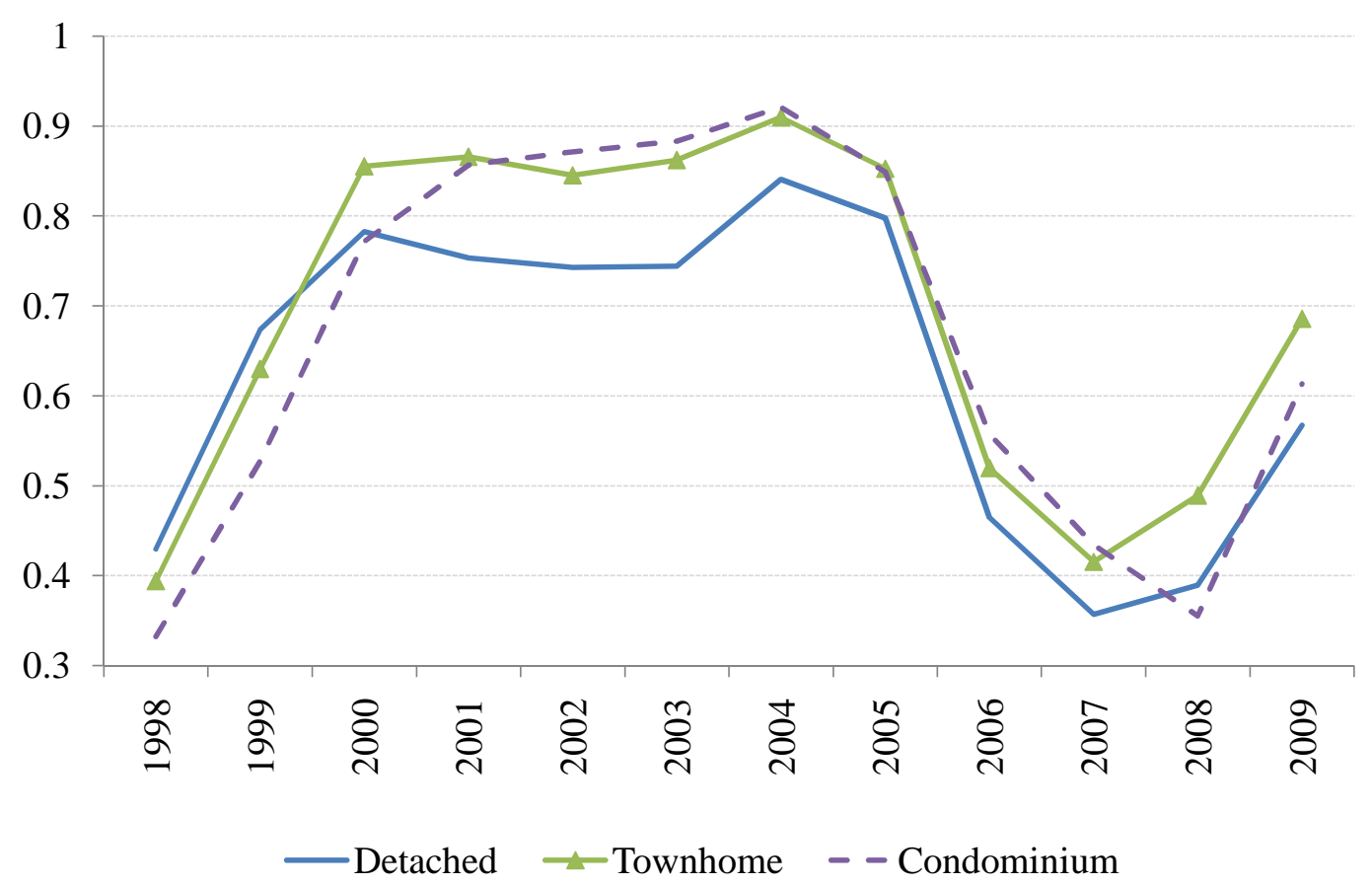

Note: Seller's bargaining power has been computed using equation (26) and aggregate annual data from Fairfax County, VA.

Figure 8

Seller's Bargaining Power by Age

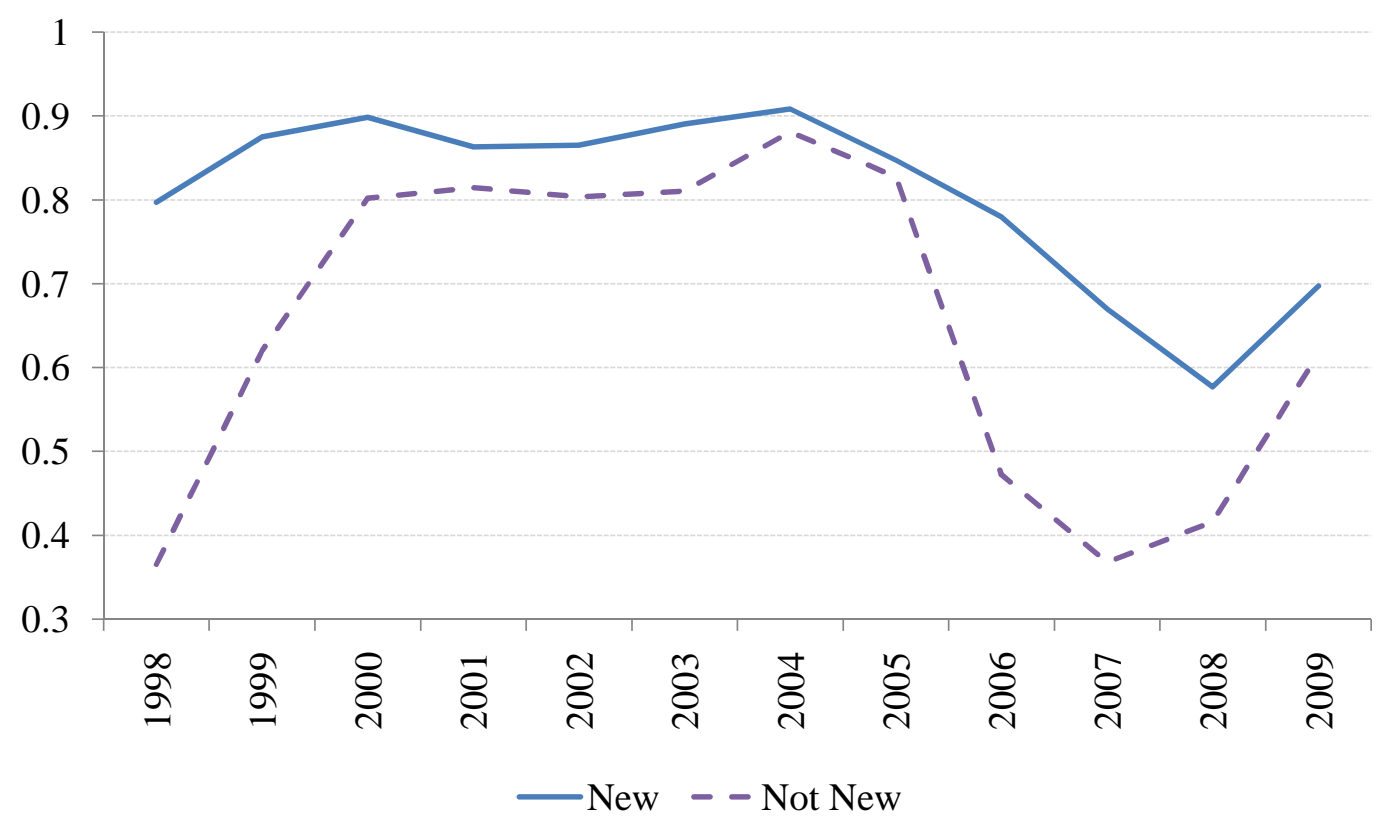

Note: Seller's bargaining power has been computed using equation (26) and aggregate annual data from Fairfax County, VA. 